\title{
Biological Oceanography by Remote Sensing
}

\author{
M.A. Srokosz
}

in

Encyclopedia of Analytical Chemistry

R.A. Meyers (Ed.)

pp. 8506-8533

(C) John Wiley \& Sons Ltd, Chichester, 2000 



\section{Biological Oceanography by Remote Sensing}

\author{
M.A. Srokosz \\ Southampton Oceanography Centre, \\ Southampton, $U K$
}

\section{Introduction}

1.1 A Brief History of Ocean Color Measurements from Space

\section{Light in the Ocean}

2.1 Some Definitions

2.2 In-water Constituents and Bio-optics

2.3 Measurements from Space and the

Effect of the Atmosphere

2.4 Case 1 and Case 2 Waters

3 Satellites and Sensors

3.1 Missions and Sensors Characteristics

3.2 Algorithms, Including Atmospheric Correction

3.3 Calibration and Validation

4 Applications

4.1 Measurements of Phytoplankton

4.2 The $\mathrm{CO}_{2}$ Problem

4.3 Biophysical Interactions

4.4 Assimilation of Data into Models

4.5 Dimethyl Sulfide, Climate, and Gaia

4.6 Commercial Application - Fisheries

4.7 Possible Future Applications

4.8 Afterword

Acknowledgments

Abbreviations and Acronyms

Related Articles

References

Biological oceanography may be studied from space using sensors on satellites that determine the color of the ocean. The presence of phytoplankton (microscopic algae) in the upper layers of the ocean changes the color of the water as seen from above. In simplified terms, this is due to the selective absorption of blue light by the phytoplankton pigments (primarily chlorophyll) which changes the appearance of the water from blue to green. These changes in color can be observed using a satelliteborne spectroradiometer that measures the water-leaving radiance in a number of bands in the visible part of the electromagnetic spectrum. The limitations of the technique

are first, that only information on the phytoplankton in the upper layers of the ocean can be obtained (light does not penetrate very far into the ocean). Second, most of the signal measured by the satellite sensor originates in the atmosphere (due to the molecular and aerosol scattering of photons there), so careful correction for atmospheric effects is necessary if good ocean data are to be obtained. Of course, in the presence of clouds the sensor will not "see" the ocean surface at all, and no data will be obtained. Third, only one component of the ocean ecosystem, namely the phytoplankton, can be studied by this means. Despite these limitations, satellite observations of ocean color have given new insights into biological oceanography on a global scale that could not have been obtained by any other means of observation. Observations of ocean color have contributed to a better understanding of the biophysical interactions that determine the phytoplankton productivity, the seasonal and interannual variations of the phytoplankton biomass on global scales, and the role of phytoplankton in the climate system. They have also contributed to the improved modeling of biogeochemical processes in the ocean.

\section{INTRODUCTION}

The purpose of this article is to describe the application of satellite remote sensing techniques to the study of biological oceanography. In one sense it seems strange to think that a sensor (instrument) flying on a satellite several hundreds of kilometers above the ocean surface can tell us anything at all about the biology of the ocean. This initial reaction is to a large extent correct, in that measurements from space can only tell us something directly about one very specific component of the ocean biology. That component is the phytoplankton, microscopic plants that live in the near-surface waters of the ocean. The reason that this component can be observed from space is that the phytoplankton contain pigments that are necessary for photosynthesis (primarily chlorophyll-a) and their presence in the water changes the color of the water, as seen from above the sea surface, usually from blue to green. Thus a satellite-borne sensor that makes measurements in the visible part of the electromagnetic spectrum can be used to measure the change in color, and so provide information on the phytoplankton.

Given that only a single component of the ocean biological system can be measured from space, one might ask: why bother? Plankton are the most abundant life form in the world's oceans, both in terms of weight and of numbers. Phytoplankton are microscopic plants, while zooplankton are the microscopic and small animals that feed on the phytoplankton. A cubic meter of seawater 
will contain millions of these small plants. Phytoplankton are the oceanic equivalent of terrestrial plants, forming the basic element of the oceanic food chain. The total phytoplankton biomass is greater than that of all the marine animals taken together (zooplankton, fish, and so on). In addition to their role in the food chain, they have a significant role in the world's climate system. Their presence in the water causes light to be scattered and absorbed, which warms the upper layers of the ocean. They produce chemical compounds that escape into the atmosphere and have a role in the formation of clouds. More fundamentally, in growing they use carbon dioxide from the atmosphere that has been absorbed into the ocean. When they die, some proportion of the plankton fall out of the upper layers of the ocean and become part of the seabed sediments, thus removing carbon from the system. Therefore, phytoplankton have a major role in the global carbon cycle and may be important in either ameliorating or accelerating the effects of anthropogenic emissions of $\mathrm{CO}_{2}$ into the atmosphere. At the present time it is not known how the phytoplankton will respond to the warming occurring due to the increase of greenhouses gases. ${ }^{(1)}$

The preceding paragraph shows the importance of phytoplankton and why measuring them and their behavior is necessary, but why do it from space? As noted above, phytoplankton are ubiquitous in the world's oceans, but the traditional ship-based methods of observation are unable to give a truly global view of the phytoplankton in the ocean. Thus observations from space are the only means of obtaining a global view. In order to understand the oceanic ecosystem, of which phytoplankton are just one component, ship-based and other types of measurements are still necessary. However, the ability to measure one component of the system from space has brought many new insights into the biology of the ocean on the global scale. These will be described later in this article.

There are, of course, drawbacks to measuring phytoplankton by satellite remote sensing methods. Since the measurement of ocean color is made using the visible part of the electromagnetic spectrum, the major problem that arises is the presence of clouds, which prevents the sensor from seeing the sea surface and thus making measurements. (Other satellite sensors that measure in a different part of the electromagnetic spectrum, particularly the microwave part, can see through clouds, but do not provide information on ocean biology directly). ${ }^{(2-4)}$ As some areas of the world's oceans are more prone to cloud cover than others this could lead to bias in the measurements. A second problem is that of the depth of penetration of light into the ocean. The satellite sensor measures light exiting from the sea surface representing the end-result of complex interactions (absorption and scattering) of the light entering the ocean with the constituents (such as phytoplankton) present in the water, and the water itself. Depending on the constituents present, the exiting light represents information about the constituents over some depth (the details of this will be considered further below). This depth varies from place to place, so interpretation of the measurements may not be straightforward. A particular example of this problem is that of the socalled deep chlorophyll maximum. ${ }^{(5)}$ This occurs when the surface waters are depleted of the nutrients necessary for the phytoplankton to grow. Here the balance between the phytoplankton's need for light (available from above) and nutrients (available from below) to grow, means that the bulk of the phytoplankton growth takes place well below the surface and may not be visible to the satellite sensor. Thus any estimate of phytoplankton activity, particularly primary production, based on ocean color measured from space will need to account for this type of situation.

Despite the drawbacks mentioned in the previous paragraph, the ability to measure ocean color from space has brought many new insights into ocean biology and these will be described later in this article. To begin, a brief history of the measurement of ocean color from space will be given.

\subsection{A Brief History of Ocean Color Measurements from Space}

The first true ocean color sensor was the Coastal Zone Color Scanner (CZCS), which was launched by NASA (National Aeronautical and Space Administration) on the Nimbus-7 satellite in late 1978 and operated until mid-1986. ${ }^{(6)}$ This followed on from the work of Clarke et al. ${ }^{(7)}$ who showed that chlorophyll concentration in the ocean surface waters could be estimated from airborne measurements of the light leaving the sea surface. CZCS made measurements in four channels in the visible part of the spectrum, one channel in the near-infrared, and one in the infrared (IR) (see Table 2 for details of the sensor). The latter channel allowed simultaneous measurement of the sea surface temperature (SST), but failed early in the mission. In addition, the sensor showed degradation over the life of the mission, which meant that the data had to be carefully processed to take this into account. ${ }^{(8)}$ A final drawback was that data were not acquired continuously globally during the mission, owing to the limits of power and on-board data recording. Nevertheless, data from most parts of the globe were acquired and the first truly global picture of phytoplankton activity in the ocean was obtained by averaging the data over time.

The next sensor due to be launched was the Seaviewing Wide Field-of-view Sensor (SeaWiFS) flown on SeaStar, but various delays meant the Ocean Color and 
Temperature Sensor (OCTS) was launched first by the National Space Development Agency of Japan (NASDA) on ADEOS (Advanced Earth Observation Satellite). OCTS was operational from August 1996 until June 1997, when the ADEOS suffered a catastrophic failure (Tables 3 and 4). In addition to measuring ocean color, OCTS measured SST using channels in the IR. SeaWiFS, a collaborative venture between NASA and the Orbital Sciences Corporation (OSC), was launched in August 1997, shortly after the failure of ADEOS. It continues to operate well and provide data globally (Table 5). Both SeaWiFS and OCTS have more channels in the visible part of the spectrum than CZCS, and this allows for better retrieval of biological information from the ocean (see section 3).

Another sensor that is flying in space, on the Indian IRS-P3 satellite, is an experimental one developed by DLR (German Space Agency) in Germany, the Modular Optoelectronic Scanner (MOS). It was launched in March 1996 and does not provide global data. It does have similar channels in the visible part of the spectrum to OCTS and SeaWiFS, but a much narrower swath $(200 \mathrm{~km})$. Two further sensors capable of measuring ocean color are due to be launched. The Moderate Resolution Imaging Spectroradiometer (MODIS) is due to be launched by NASA on the first Earth Observing System (EOS) platform in late 1999. ${ }^{(9)}$ The Medium Resolution Imaging Spectrometer (MERIS) is due for launch in early 2001 on the European Space Agency's (ESA) satellite Envisat. ${ }^{(10)}$ Both sensors have more channels than OCTS and SeaWiFS (Tables 6, 7 and 8). MODIS and MERIS are not just designed for ocean color measurements but will also provide data on the atmosphere, and on terrestrial vegetation. Finally, the experimental Ocean Color Imager (OCI) is due to be launched on the Taiwanese satellite ROCSAT-1 in 1999.

The above discussion has given details of the sensors that have specific ocean color capability, but it is also worth noting that other sensors that measure in the visible part of the spectrum have been used occasionally. ${ }^{(2)}$ In general, these sensors are not sufficiently sensitive for ocean color measurements, an exception being the detection of coccolithophore blooms using the visible band of AVHRR (advanced very high resolution radiometer); an instrument designed for measuring SST. Owing to their high reflectivity, coccolithophores can be seen by less-sensitive sensors such as AVHRR (see section 4.1.3 below). In this article the focus will be on those sensors specifically designed for ocean color measurements.

In order to understand how it is possible to obtain information about biological activity from satellite ocean color sensors, it is necessary to consider first the behavior of light in the ocean. This is the subject of the next section (section 2). Following this a more detailed description of the sensors and algorithms used to retrieve ocean color and biological information is given (section 3 ). Finally (section 4) the application of that information to study ocean biology will be discussed.

\section{LIGHT IN THE OCEAN}

The subject of light in the ocean is a vast one, as evidenced by the more than one thousand references given in a standard text by Kirk. ${ }^{(11)}$ It is not possible in a brief article to do justice to all these aspects, so the focus will be on those most relevant to the remote sensing of ocean color. In this context light will be taken to mean electromagnetic radiation of wavelengths ca. $400-700 \mathrm{~nm}$, to which the human eye responds, and which plants, including phytoplankton, can use for photosynthesis. ${ }^{(11,12)}$ In terms of color, blue light has wavelengths of ca. $450 \mathrm{~nm}$, green light ca. $520 \mathrm{~nm}$ and red light ca. $650 \mathrm{~nm}$. The light of wavelengths $400-700 \mathrm{~nm}$ is usually referred to as photosynthetically active (or available) radiation (PAR). ${ }^{11,13)}$

\subsection{Some Definitions}

Light (photons) entering the ocean is subject to two physical processes, absorption and scattering (for more details of the definitions in this section see Mobley ${ }^{(14)}$ and $\left.\operatorname{Kirk}^{(11)}\right)$. The description of the optical properties associated with these processes is usually divided into inherent and apparent optical properties (IOPs and AOPs). IOPs depend only on the medium and can be specified for light of any given wavelength $\lambda$ by the absorption and scattering coefficients, $a(\lambda)$ and $b(\lambda)$, and the volume scattering function, which describes the directional properties of the scattering. The AOPs depend both on the medium (thus on the IOPs) and on the geometric structure of the ambient light field. Examples of AOPs are the diffuse, or vertical, attenuation coefficients $K(\lambda, z)$, which describe the approximately exponential decrease with depth $z$ of various properties of the light field. The IOPs and the AOPs depend on both the water and on what is in the water, for example, phytoplankton.

In terms of the light properties of interest in remote sensing, the important quantities are radiance, irradiance, upwelling (upward) and downwelling (downward) irradiance, diffuse attenuation coefficient, and the optical depth. These are all considered to depend on the frequency or wavelength of the light, as ocean color sensors measure light in discrete bands of the electromagnetic spectrum. Therefore, in terms of wavelength, they are expressed in units as per nanometer $\left(\mathrm{nm}^{-1}\right)$, that is per unit spectral bandwidth. Equivalent quantities integrated 
over part or the whole of the visible spectrum are defined without $\mathrm{nm}^{-1}$. Radiance $L(\lambda)$ is the optical property appropriate to light energy leaving an extended source or incident on a surface, such as the ocean, and has units of $\mathrm{W} \mathrm{m} \mathrm{m}^{-2} \mathrm{sr}^{-1} \mathrm{~nm}^{-1}$ (the last but one factor is per steradian, a measure of solid angle). Irradiance $E(\lambda)$ is the radiant flux per unit area of a surface and has units of $\mathrm{W} \mathrm{m}^{-2} \mathrm{~nm}^{-1}$. Downwelling irradiance $E_{\mathrm{d}}(\lambda)$ and upwelling irradiance $E_{\mathrm{u}}(\lambda)$, are the values of the flux passing down, or up, through a horizontal surface. $E_{\mathrm{d}}$ and $E_{\mathrm{u}}$ are obtained from $L$, the radiance incident on the surface, by integrating with respect to the solid angle $w$ for the upper and lower hemispheres, respectively, see Equations (1) and (2). Thus

$$
\begin{aligned}
& E_{\mathrm{d}}=\int_{\text {upper hemisphere }} L \cos v \mathrm{~d} w \\
& E_{\mathrm{u}}=-\int_{\text {lower hemisphere }} L \cos v \mathrm{~d} w
\end{aligned}
$$

where $v$ is the zenith angle. ${ }^{(11)}$ The diffuse or vertical attenuation coefficient at a depth $z$ is given by Equation (3)

$$
K(\lambda, z)=\frac{-1}{E(\lambda, z)} \frac{\mathrm{d} E}{\mathrm{~d} z}
$$

and has units of $\mathrm{m}^{-1}$. If $K_{\mathrm{d}}$ does not vary much with depth, an optical depth can be defined as $1 / K_{\mathrm{d}}$, where $K_{\mathrm{d}}$ is the diffuse attenuation coefficient for the downwelling irradiance $E_{\mathrm{d}}$. It can be shown that the information on chlorophyll concentration obtained from an ocean color sensor is that from approximately one optical depth, which can be regarded as the depth that the sensor sees into the ocean. ${ }^{(15)}$

The key quantity of interest in measuring ocean color from space is the water-leaving radiance $L_{\mathrm{w}}$. This represents the light leaving the sea surface resulting from the absorption and scattering by the water itself and by in-water constituents, such as phytoplankton, of light incident on the sea surface. It is this light that contains information about what is in the water. However, the light (radiance) that the satellite sensor measures $L_{\mathrm{s}}$ originates from a number of sources (see, for example, Robinson ${ }^{(2)}$ or Kirk $\left.{ }^{(11)}\right)$. Even in relatively clear atmospheric conditions $L_{\mathrm{w}}$ is only $10-20 \%$ of $L_{\mathrm{s}} .{ }^{(11)}$ This means that the effect of the atmosphere must be accounted for in deriving $L_{\mathrm{w}}$ from $L_{\mathrm{s}}$. This problem is discussed in section 2.3 below. For various technical reasons that will not be discussed here, two other related quantities are sometimes used in the measurement of ocean color rather than $L_{\mathrm{w}}$. These are the normalized water-leaving radiance; that is, approximately the radiance that would exit the ocean in the absence of the atmosphere and with the sun at the zenith. ${ }^{(16)}$
Another alternative to $L_{\mathrm{w}}$ is the reflectance $\rho_{\mathrm{w}}$; that is, $L_{\mathrm{w}}$ normalized with respect to the extraterrestrial solar irradiance. ${ }^{(16)}$ The important point to note is that whichever quantity is used it can be related to the presence of phytoplankton in the water, which will be discussed in the next subsection.

The final definition to be given in this section is that of the euphotic zone. Kirk ${ }^{(11)}$ states that a useful rule of thumb in aquatic biology is that significant phytoplankton photosynthesis takes place down to a depth $z_{\mathrm{e}}$ at which the downwelling irradiance of PAR falls to $1 \%$ of its value just below the sea surface. The layer in which $E_{\mathrm{d}}(\mathrm{PAR}, z)$ is greater than or equal to $1 \%$ of $E_{\mathrm{d}}(\mathrm{PAR}$, $0)$ is known as the euphotic zone. It can be shown that the depth that the ocean color sensor sees into the ocean is approximately $z_{\mathrm{e}} / 4.6$ (one optical depth). In waters with a low concentration of chlorophyll $\left(0.1 \mathrm{mg} \mathrm{m}^{-3}\right)$ this depth is about $25 \mathrm{~m}$, whereas for waters with a higher concentration $\left(10 \mathrm{mg} \mathrm{m}^{-3}\right)$ it is about $5 \mathrm{~m} .{ }^{(17)}$ High concentrations of chlorophyll reduce the penetration of light into the ocean, owing to absorption and scattering.

\subsection{In-water Constituents and Bio-optics}

In simple terms the presence of phytoplankton in the water changes the color of the water as seen by the color sensor. Waters low in phytoplankton pigments reflect more blue light than green, whereas waters high in pigments reflect more green light as a result of the selective absorption of blue light by the pigments. This means that the shape of the light spectrum changes and by measuring in different bands of the spectrum it is possible to quantify the concentration of pigment present in the water. ${ }^{(2,11)}$ The pigments that absorb the light are chlorophyll-a and phaeopigments, so the estimate obtained from the color data is the pigment concentration. However, the phaeopigments are a small fraction of the total (ca. $10 \%),{ }^{(18)}$ so the pigment concentration can be regarded as the chlorophyll-a concentration in the case of CZCS, owing to the inherent error in the algorithms used to recover this information (section 3.2). In the section on applications, the terms chlorophyll concentration or pigment concentration will both be used when discussing CZCS data. In order to extract the pigment concentration information from the ocean color measurements it is necessary to develop bio-optical algorithms and the theoretical basis of these is considered next.

It can be shown theoretically that the waterleaving radiance $L_{\mathrm{w}}(\lambda)$ is related to the reflectance $R(\lambda)=E_{\mathrm{u}}(\lambda) / E_{\mathrm{d}}(\lambda)$ evaluated just below the sea surface. ${ }^{(2,15)}$ Theoretical modeling suggests that $R(\lambda)$ in turn depends on the absorption $a(\lambda)$ and backscattering $b_{\mathrm{b}}(\lambda)$ coefficients (note that the scattering coefficient $b(\lambda)=b_{\mathrm{b}}(\lambda)+b_{\mathrm{f}}(\lambda)$, the scattering in the backward and 
forward directions $\left.{ }^{(11)}\right)$. For $b_{\mathrm{b}} / a$ small, $R=0.33 b_{\mathrm{b}} / a ;^{(2,19)}$ more generally $R$ may be regarded as a function of $\left[b_{\mathrm{b}} /\left(a+b_{\mathrm{b}}\right)\right] .^{(2,20)}$ In addition, the absorption and scattering coefficients can be decomposed into the contributions due to the water itself and to each of the constituents in the water, and so related to the chlorophyll concentration. On this basis it is possible to develop what are known as semianalytical models of ocean color, where the behavior of $a(\lambda)$ and $b_{\mathrm{b}}(\lambda)$ is established through a combination of modeling and measurements. ${ }^{(20)}$ For CZCS the standard algorithms were in fact based on an empirical approach, where the ratio of the water-leaving radiance in two bands was compared to values of the pigment concentration measured in situ (section 3.2). ${ }^{(15)}$ This is a simple measurement that compares the waterleaving radiance in the blue to that in the green part of the visible spectrum, the ratio decreasing with increasing concentration of pigments. ${ }^{(20)}$ For future missions both empirical and semianalytical approaches to estimating pigment concentration will be used (see, for example, Esaias et al. $\left.{ }^{(9)}\right)$. In principle, the semianalytical approach should provide improved information as it should reduce some of the uncertainties associated with the empirical approach. ${ }^{(20)}$ In either case accurate measurements of the water-leaving radiance in the sensor bands need to be obtained and this requires that the data be corrected for atmospheric effects, which are discussed next.

\subsection{Measurements from Space and the Effect of the Atmosphere}

It is well known that at least $80-90 \%$ of the signal received by an ocean color sensor at the top of the atmosphere originates from the atmosphere rather than the ocean, even in relative clear atmospheric conditions. ${ }^{(11)}$ In the presence of clouds no signal from the sea surface is obtained at all, of course. Therefore the removal of the atmospheric effects from the signal received by the sensor is crucial if accurate measurements of the water-leaving radiance in the various sensor bands are to be obtained. The signal received by the satellite sensor may be written as Equation (4) ${ }^{(9)}$

$$
\begin{aligned}
L_{\mathrm{s}}(\lambda)= & L_{\mathrm{r}}(\lambda)+L_{\mathrm{a}}(\lambda)+L_{\mathrm{ra}}(\lambda)+T(\lambda) L_{\mathrm{sg}}(\lambda) \\
& +t(\lambda) L_{\mathrm{wc}}(\lambda)+t(\lambda) L_{\mathrm{w}}(\lambda)
\end{aligned}
$$

where $L_{\mathrm{r}}$ is the scattering of the photons due to air molecules (known as Rayleigh scattering), $L_{\mathrm{a}}$ is the scattering due to atmospheric aerosols (dust, water droplets, salt, and so on), $L_{\mathrm{ra}}$ represents interactions between the two previous effects, $L_{\mathrm{sg}}$ is the sunglint contribution (the direct reflection of sunlight from the sea surface), $L_{\mathrm{wc}}$ is the whitecap contribution (due to the presence of breaking waves), and $L_{\mathrm{w}}$ is the desired water-leaving radiance. $T$ and $t$ are the direct and diffuse transmittance of the atmosphere, that is the effects of the atmosphere on the signal from the sea surface. Sunglint cannot be corrected for, so data contaminated by sunglint are usually discarded. ${ }^{(16)}$ Considerable effort has been devoted to obtaining accurate corrections with regard to the other terms. Gordon ${ }^{(16)}$ gives a comprehensive review.

As the applications discussed later are based on data from the CZCS instrument, a brief explanation of the atmospheric correction technique developed for it will be given here. The ability to correct for atmospheric effects is partly dependent on the measurements made by the sensor. If measurements are obtained in a sufficient number of independent bands in the electromagnetic spectrum, then the effects of the atmosphere can be accounted for (to a lesser or greater degree depending on what is in the atmosphere). As CZCS had only four bands in the visible, the possibilities for atmospheric correction were limited, so simplifying assumptions were made. In particular, the Rayleigh scattering was assumed to be single scattering (photons have only one scattering encounter with air molecules) and this can be calculated theoretically, as can the diffuse transmittance of the atmosphere. The interaction term between the aerosol scattering and Rayleigh scattering term was ignored (being a secondary effect). The effect of whitecaps on the sea surface was also ignored.

The aerosol scattering term was treated in a simplified manner (see the appendix of Gordon et al. ${ }^{(20)}$ ). If the water-leaving radiance is known in two bands at one position then the ratio $S\left(\lambda_{1}, \lambda_{2}\right)=L_{\mathrm{a}}\left(\lambda_{1}\right) / L_{\mathrm{a}}\left(\lambda_{2}\right)$ may be found ( $L_{\mathrm{w}}$ known, $L_{\mathrm{s}}$ measured, $t$ and $L_{\mathrm{r}}$ calculated, all other terms ignored). Making the assumptions that the aerosol scattering phase function is approximately independent of wavelength, it can be shown under the single scattering approximation that $S\left(\lambda_{1}, \lambda_{2}\right)=$ $\varepsilon\left(\lambda_{1}, \lambda_{2}\right) F\left(\lambda_{1}\right) / F\left(\lambda_{2}\right)$, where the $F$ s represent the ratio of the extraterrestrial solar irradiance for the two wavebands, corrected for absorption by atmospheric ozone, and $\varepsilon\left(\lambda_{1}, \lambda_{2}\right)$ is the ratio of the aerosol optical thicknesses at $\lambda_{2}$ and $\lambda_{1} . \varepsilon$ depends only on the type of aerosol present in the atmosphere and not its concentration. For the ocean a reasonable assumption is that the aerosol type is the same across an image and only the concentration varies. Thus if $\varepsilon$ can be determined for the pairs of CZCS bands somewhere in an image, then the water-leaving radiances can be calculated for the whole image. This was done based on the clear water radiance concept which gives $L_{\mathrm{w}}(520), L_{\mathrm{w}}(550)$ and $L_{\mathrm{w}}(670)$ when the pigment concentration is less than $0.25 \mathrm{mg} \mathrm{m}^{-3}$. This allows $\varepsilon(520,670)$ and $\varepsilon(550,670)$ to be determined for pixels satisfying the clear water condition, and $\varepsilon(443,670)$ is extrapolated from these values. The further assumption 
that $L_{\mathrm{w}}(670)=0$ then allows the water-leaving radiance in the other three bands to be determined. This is based on the fact that water absorbs light strongly in the red/near-IR region of the spectrum, ${ }^{(11)}$ which is a reasonable assumption for clear oceanic waters. There are problems with this approach if there is no clear water in the image or if the aerosol type varies across the image. For the first problem, an iterative approach is possible by starting with an initial guess for $L_{\mathrm{w}}(670){ }^{(20,21)}$ The second problem, together with the problems due to the simplifying assumptions made in the CZCS approach, can only be dealt with by a more sophisticated pixel by pixel atmospheric correction procedure, which can incorporate the information available from the extra channels of the new sensors. These are being developed and applied. ${ }^{(16,22)}$

The CZCS atmospheric correction procedure worked reasonably well for the open ocean, but less well in coastal areas. It is not valid to make assumptions about the constancy of aerosol type near land, and about the water-leaving radiance in the red/near-IR region when there are sediments in the water. ${ }^{(11,21)}$ For reasons like these it has proved useful to distinguish between two different water types when using the data from color sensors, as explained in the next section.

\subsection{Case 1 and Case 2 Waters}

Before proceeding further in the discussion of ocean color measurements it is necessary to define the terms Case 1 and Case 2 waters, which are often used in the remote sensing of ocean color. These terms were originally used by Morel and Prieur. ${ }^{(19)}$ Case 1 waters are ones where the optical signature is due to the presence of phytoplankton and their by-products. Case 2 waters are ones where the optical signature may also be influenced by the presence of suspended sediments, dissolved organic matter and terrigenous particles from rivers and glaciers. In general, Case 1 waters are those of the open ocean, while Case 2 waters are those of the coastal seas. The derivation of geophysical parameters from Case 2 waters is much more complex, as the presence of the various particulates in the water, in addition to the phytoplankton, affects the color signal measured by the satellite sensor. ${ }^{(2,23)}$ This also makes atmospheric correction of the data more difficult (see section 2.3). Given these complications and that the focus of this article is on biological oceanography, further discussion will be restricted to Case 1 waters. It is worth noting that the new generation of satellite sensors (SeaWiFS, MODIS, MERIS; see next section) which possess more bands in the visible part of the spectrum than did CZCS, will allow better discrimination between the various in-water constituents in Case 2 waters. ${ }^{(24)}$ Almost all the applications of ocean color data that will be discussed below (section 4) will be from open ocean Case 1 waters.

\section{SATELLITES AND SENSORS}

From the previous section, it is clear that it is necessary to measure the spectral properties of the light leaving the ocean, and to correct for the effects of the intervening atmosphere on the measurements, in order to obtain useful biological measurements from spaceborne sensors. In this section, the characteristics of various ocean color sensors that have been, or will be, flown in space are described. In addition, an overview of the algorithms used to derive biological information will be presented together with an explanation of how these have been calibrated and validated.

\subsection{Missions and Sensors Characteristics}

As noted in the historical introduction (section 1.1) a number of ocean color sensors have been or are to be flown in space. The characteristics of each sensor will be given in the following subsections. Here a summary of the instruments and satellites is provided in Table 1. (The experimental sensors MOS and OCI mentioned in the historical survey have been excluded from what follows.) Details of earlier visible band sensors that were not specifically designed for ocean color studies but have been used for such may be found in Robinson ${ }^{(2)}$ and Stewart. ${ }^{(3)}$

Optical sensors are essentially of two types, pushbroom or scanning. Pushbroom sensors have optics that enable a line of data, in an across-track direction, to be acquired at the same time. Scanning sensors have optics that scan in the across-track direction, thus acquiring a line of data. The swath width of the sensor is determined by the height above the surface and the maximum angle of view acrosstrack to either side of nadir. The instantaneous field of view (IFOV) of the sensor fixes the size of the pixels that make up each line of data. The angular resolution of the sensor's optical system and the height of the satellite orbit determine the IFOV. Owing to the viewing geometry, for a fixed angular resolution, this means that pixels at nadir are somewhat smaller than those out towards the edge of the instrument swath. An image is built up of successive

Table 1 Ocean color sensors and satellites

\begin{tabular}{|c|c|c|c|}
\hline Sensor & Satellite & Agency & Dates \\
\hline CZCS & Nimbus-7 & NASA & $10 / 78-6 / 86$ \\
\hline OCTS & ADEOS & NASDA & $8 / 96-6 / 97^{a}$ \\
\hline SeaWiFS & SeaStar & OSC/NASA & launched 8/97 \\
\hline MODIS & $\begin{array}{l}\text { EOS-AM1 } \\
\text { EOS-PM1 }\end{array}$ & NASA & $\begin{array}{l}\text { due for launch } 1999 \\
\text { due for launch } 2000\end{array}$ \\
\hline MERIS & Envisat & ESA & due for launch 2001 \\
\hline
\end{tabular}

${ }^{\text {a }}$ Mission ended prematurely owing to unfortunate catastrophic failure of ADEOS satellite. 
lines of data as the satellite moves along its orbit. Some optical sensors flown in space also have the capability to tilt, thus being able to look ahead or behind the satellite, rather than just down at nadir. This capability is used to avoid sunglint problems over certain parts of the satellite's orbit, by tilting the sensor away from the sunglint (the direct reflection of the sun in the sea surface). Clearly the degree of tilt will affect both the swath width and the pixel size.

In the following, details of the individual sensors will be given, including the type of sensor (pushbroom or scanning, tilting or nontilting), the orbit height, the swath width, the spatial resolution (pixel size) and, most important, the bands in the electromagnetic spectrum in which each sensor measures. At the typical orbit altitudes and swath widths of the satellites and sensors, respectively, global coverage of the oceans is acquired over about three days (on-board recording capability permitting).

\subsubsection{Coastal Zone Color Scanner}

CZCS was a scanning sensor able to scan $\pm 39.34^{\circ}$ each side of nadir. The satellite altitude of $955 \mathrm{~km}$ meant that the resulting swath width was $1659 \mathrm{~km}$ when the sensor was in nadir-looking mode. The sampling of the scan was such as to give 1968 pixels across the swath. The sensor could tilt $\pm 20^{\circ}$, in steps of $2^{\circ}$ to avoid sunglint. The IFOV (ca. $0.05^{\circ}$ ) gave pixels that varied from $825 \mathrm{~m}$ at nadir to $1653 \mathrm{~m}$ at the edge of the swath (again in nadir-looking mode). The swath width and pixel size varied with the degree of tilt. The sensor had six channels (Table 2), four in the visible part of the spectrum, one in the near-IR, and one in the thermal IR. ${ }^{21,25)}$

Owing to limitation of power on board the Nimbus-7 satellite, CZCS was limited to only two hours of operation each day. Furthermore, limited data-recording capability meant that much of the data had to be acquired when the satellite was within reception range of a ground recording station. When combined with the problems of cloud cover this meant that, over its lifetime 1978-1986, CZCS data coverage was somewhat patchy. Despite this, it provided the first global view of the biology of the oceans and

Table 2 CZCS bands

\begin{tabular}{lccc}
\hline Band no. & $\begin{array}{c}\text { Band center } \\
(\mathrm{nm})\end{array}$ & $\begin{array}{c}\text { Band width } \\
(\mathrm{nm})\end{array}$ & $\mathrm{S} / \mathrm{N}$ \\
\hline 1 & 443 & 20 & 350 \\
2 & 520 & 20 & 342 \\
3 & 550 & 20 & 280 \\
4 & 670 & 20 & 209 \\
5 & 750 & 100 & 50 \\
6 & 11500 & 2000 & Thermal IR band \\
\hline
\end{tabular}

$\mathrm{S} / \mathrm{N}$, Signal-to-noise ratio. subsequent work on the data has produced a calibrated and consistent data set for that period. ${ }^{(6)}$

Over its period of operation the visible band detectors were found to be suffering from decreasing and variable sensitivity, ${ }^{(8,15)}$ and careful correction for this effect was necessary in order to make full use of the data. ${ }^{(8)}$ The broad near-IR band (band 5; see Table 2) was only useful for land-sea-cloud discrimination. In addition, the thermal IR band detector failed shortly after launch so that SST data were not available. Most of the processing effort has therefore focused on data from the four visible bands (bands 1 to 4$)$. ${ }^{(21)}$

\subsubsection{Ocean Color and Temperature Sensor}

After a gap of 10 years from the demise of CZCS, OCTS was launched in August 1996. Unfortunately the mission was short lived as the ADEOS satellite suffered a catastrophic failure in June 1997, thus acquiring only nine months of data. Although launched prior to SeaWiFS (which was to have been launched about 1994), OCTS was designed in the light of SeaWiFS and was therefore in some respects a very similar instrument. It had six visible bands and two near-IR bands, which corresponded very closely to the SeaWiFS bands (compare Tables 3 and 5). In addition, OCTS had four bands in the thermal IR (see Table 4) which allowed the retrieval of SST, thus providing contemporaneous information on ocean biology (from color) and physics (from SST). The spatial resolution at nadir was approximately $700 \mathrm{~m}$. The nominal orbit altitude was $700 \mathrm{~km}$, giving a swath width of about $1400 \mathrm{~km}$. The sensor was of the scanning type, with the ability to tilt $\pm 20^{\circ}$ forward and backwards to avoid sunglint. ${ }^{(26)}$

\subsubsection{Sea-viewing Wide Field-of-view Sensor}

SeaWiFS was designed as the successor to CZCS, but for a variety of reasons its launch was delayed until

Table 3 OCTS visible bands

\begin{tabular}{lccc}
\hline Band no. & $\begin{array}{c}\text { Band center } \\
(\mathrm{nm})\end{array}$ & $\begin{array}{c}\text { Bandwidth } \\
(\mathrm{nm})\end{array}$ & Comments \\
\hline 1 & 412 & 20 & \\
2 & 443 & 20 & \\
3 & 490 & 20 & \\
4 & 520 & 20 & \\
5 & 565 & 20 & Atmospheric correction \\
6 & 665 & 20 & \\
7 & 765 & 40 & \\
8 & 865 & 40 & Atmospheric correction \\
\hline \multicolumn{5}{c}{ Table 4 OCTS thermal bands $(\mu \mathrm{m})$} & $11.4-12.5$ \\
\hline $3.55-3.88$ & $8.25-8.80$ & $10.3-11.4$ & \\
\hline
\end{tabular}


August 1997, over 10 years after the demise of CZCS. It is now in orbit and providing very high quality ocean color data. Unlike CZCS, it has no bands in the IR, so provides no information on SST (its successor MODIS will have IR bands, see section 3.1.4). A comparison of the capabilities of CZCS and SeaWiFS is given by Hooker et al. ${ }^{(25)}$ SeaWiFS flies on the SeaStar satellite operated by OSC, with NASA buying the data for distribution to the scientific community, while OSC sell the data to commercial organizations for other applications (see section 4.6).

SeaWiFS has six bands in the visible part of the electromagnetic spectrum and two bands in the nearIR for atmospheric correction purposes. ${ }^{(27)}$ These bands are very similar to those of OCTS (compare Tables 3 and 5). The increased number of visible bands, plus the bands in the near-IR, and the improved sensitivity (see $\mathrm{S} / \mathrm{N}$ in Tables 2 and 5) will allow better atmospheric correction of the data and improved retrieval of biological information, compared with CZCS. ${ }^{(24)}$ SeaWiFS is a scanning instrument and has the capability to tilt $\pm 20^{\circ}$ forwards or backwards to avoid sunglint. It is operated in two spatial-resolution modes, local area coverage (LAC) with a $1.1 \mathrm{~km}$ resolution at nadir, and global area coverage (GAC) with a $4.5 \mathrm{~km}$ resolution at nadir. At the nominal orbit altitude of $705 \mathrm{~km}$, the LAC has a swath width of $2801 \mathrm{~km}$, while the GAC has a swath width of $1502 \mathrm{~km}$. The on-board recording system has only limited capacity for LAC data, so this capability is primarily for use when the satellite is within range of a ground receiving station.

\subsubsection{Moderate Resolution Imaging Spectroradiometer}

MODIS is due for launch on the EOS-AM1 satellite in late 1999. Details of the instrument may be found in Barnes et al. ${ }^{(28)}$ This instrument has 36 bands in the visible and IR part of the electromagnetic spectrum and will be used for atmospheric and terrestrial studies, as well as for biological oceanography. The bands and their uses are listed in Tables 6 and 7. At nadir, bands 1 and

Table 5 SeaWiFs bands

\begin{tabular}{lcccc}
\hline Band no. & $\begin{array}{c}\text { Band center } \\
(\mathrm{nm})\end{array}$ & $\begin{array}{c}\text { Bandwidth } \\
(\mathrm{nm})\end{array}$ & $\mathrm{S} / \mathrm{N}$ & Comments \\
\hline 1 & 412 & 20 & 499 & \\
2 & 443 & 20 & 674 & \\
3 & 490 & 20 & 667 & \\
4 & 510 & 20 & 616 & \\
5 & 555 & 20 & 581 & \\
6 & 670 & 20 & 447 & \\
7 & 765 & 40 & 455 & Atmospheric \\
& & & & correction \\
8 & 865 & 40 & 467 & Atmospheric \\
& & & & correction \\
\hline
\end{tabular}

Table 6 MODIS visible bands

\begin{tabular}{lccr}
\hline Primary use & Band no. & $\begin{array}{c}\text { Bandwidth } \\
(\mathrm{nm})\end{array}$ & $\begin{array}{c}\text { Required } \\
\text { S/N }\end{array}$ \\
\hline Land/cloud & 1 & $620-670$ & 128 \\
boundaries & 2 & $841-876$ & 201 \\
Land/cloud & 3 & $459-479$ & 243 \\
properties & 4 & $545-565$ & 228 \\
& 5 & $1230-1250$ & 74 \\
& 6 & $1628-1652$ & 275 \\
Ocean color/ & 7 & $2105-2155$ & 110 \\
phytoplankton/ & 8 & $405-420$ & 880 \\
biogeochemistry & 9 & $438-448$ & 838 \\
& 10 & $483-493$ & 802 \\
& 11 & $526-536$ & 754 \\
& 12 & $546-556$ & 750 \\
& 13 & $662-672$ & 910 \\
& 14 & $673-683$ & 1087 \\
Atmospheric & 15 & $743-753$ & 586 \\
water vapor & 16 & $862-877$ & 516 \\
& 17 & $890-920$ & 167 \\
& 18 & $931-941$ & 57 \\
& 19 & $915-965$ & 250 \\
\hline
\end{tabular}

Table 7 MODIS IR bands

\begin{tabular}{lccc}
\hline Primary use & Band no. & Bandwidth $(\mu \mathrm{m})$ & $\begin{array}{c}\text { Required } \\
\mathrm{NE} \Delta \mathrm{T}(\mathrm{K})^{\mathrm{a}}\end{array}$ \\
\hline Surface/cloud & 20 & $3.660-3.840$ & 0.05 \\
temperature & 21 & $3.929-3.989$ & 2.00 \\
& 22 & $3.929-3.989$ & 0.07 \\
Atmospheric & 23 & $4.020-4.080$ & 0.07 \\
temperature & 24 & $4.433-4.498$ & 0.25 \\
Cirrus clouds & 26 & $4.482-4.549$ & 0.25 \\
water vapor & 27 & $1.360-1.390$ & $150(\mathrm{~S} / \mathrm{N})$ \\
& 28 & $7.535-6.895$ & 0.25 \\
Ozone & 29 & $8.400-8.475$ & 0.25 \\
Surface/cloud & 30 & $9.580-9.880$ & 0.05 \\
temperature & 31 & $10.780-11.280$ & 0.25 \\
Cloud top & 33 & $11.770-12.270$ & 0.05 \\
altitude & 34 & $13.185-13.485$ & 0.05 \\
& 35 & $13.485-13.785$ & 0.25 \\
& 36 & $14.785-14.085$ & 0.25 \\
& & $14.085-14.385$ & 0.35 \\
\hline
\end{tabular}

${ }^{a} \mathrm{NE} \Delta \mathrm{T}$, Noise equivalent temperature difference.

2 have a spatial resolution of $250 \mathrm{~m}$, bands 3-7 of $500 \mathrm{~m}$ and bands $8-36$ of $1 \mathrm{~km}$. Thus the spatial resolution of the bands being used for biological oceanography (8-16) is similar to that of CZCS, OCTS, and SeaWiFS. The bands are narrower and the sensitivity greater than for the earlier instruments (see Tables 2, 3 and 5). The instrument is of the scanning type and has a swath width of $2330 \mathrm{~km}$ at its nominal operational altitude of $705 \mathrm{~km}$, with 1354 pixels across the swath. In order to obtain the best 
possible measurements the instrument has four on-board calibration systems (see Barnes et al. ${ }^{(28)}$ for details).

Although it was conceived as a two-instrument system (MODIS-T, with tilt capability, and MODIS-N, nadir looking), owing to cost constraints the tilting capability had to be foregone and a single instrument was designed. In order to compensate for the loss of oceanographic data due to sunglint (which could have been reduced using the tilt mechanism), a second MODIS instrument will be flown on the EOS-PM1 platform. It turns out that it is cheaper to design a single instrument and fly a duplicate, than to design and fly the original two-instrument system. The two instruments together will provide approximately the same global coverage as a single tilting instrument. ${ }^{(9)}$

The MODIS capabilities for ocean observations are described by Esaias et al., ${ }^{(9)}$ so only a brief summary is given here. It should be noted that MODIS's ability to measure SST (using the IR bands), in addition to ocean color, will allow it to provide data on biophysical interactions. The end-result of the improved instrument performance is the ability to obtain more information on ocean biology. Basic information derived will concern the water-leaving radiance in the various bands. From these data information on pigment concentrations, chlorophylla, coccolithophores (see section 4.1.3), phycoerythrin (a specific algal pigment), ocean primary production (see section 4.1.2), and solar-stimulated chlorophyll fluorescence will be obtained. ${ }^{(9)}$ MODIS will be the first satellite instrument to provide data on phycoerythrin and solarstimulated chlorophyll fluorescence (see section 4.7.2).

\subsubsection{Medium Resolution Imaging Spectrometer}

MERIS $^{(10)}$ is the ESA equivalent of NASA's MODIS instrument described in the previous section, but without the bands in the IR part of the electromagnetic spectrum. It too will provide data for atmospheric and terrestrial, as well as oceanographic, studies (see Table 8). MERIS is a 15-band programmable instrument, so that the band positions and widths can in principle be changed during the mission. Only 15 of the 16 preliminary bands, listed in Table 8, will be acquired and transmitted when MERIS is in orbit. It will fly on ESA's Envisat satellite at a nominal altitude of $800 \mathrm{~km}$, giving it a swath width of about $1150 \mathrm{~km}$, with 740 pixels across the swath. MERIS is a nontilting pushbroom type of instrument, so it will suffer from sunglint problems similar to MODIS.

MERIS had been designed to be useful for both global and regional studies. For this reason it has two spatial resolution modes. The so-called full-resolution mode has a resolution of $300 \mathrm{~m}$ at nadir, while the reducedresolution mode has a resolution of $1200 \mathrm{~m}$ at nadir, the latter being similar to CZCS, OCTS, SeaWiFS, and MODIS. The full-resolution mode is intended for regional
Table 8 MERIS bands

\begin{tabular}{|c|c|c|c|}
\hline Band & $\begin{array}{l}\text { Band center } \\
\quad(\mathrm{nm})\end{array}$ & $\begin{array}{l}\text { Bandwidth } \\
\quad(\mathrm{nm})\end{array}$ & Comments \\
\hline 1 & 412.5 & 10 & $\begin{array}{l}\text { Yellow substance, } \\
\text { turbidity }\end{array}$ \\
\hline 2 & 442.5 & 10 & $\begin{array}{l}\text { Chlorophyll-absorption } \\
\text { maximum }\end{array}$ \\
\hline 3 & 490 & 10 & $\begin{array}{l}\text { Chlorophyll, other } \\
\text { pigments }\end{array}$ \\
\hline 4 & 510 & 10 & $\begin{array}{l}\text { Turbidity, suspended } \\
\text { sediments, red tides }\end{array}$ \\
\hline 5 & 560 & 10 & $\begin{array}{l}\text { Chlorophyll reference, } \\
\text { suspended sediments }\end{array}$ \\
\hline 6 & 620 & 10 & Suspended sediment \\
\hline 7 & 665 & 10 & Chlorophyll-absorption \\
\hline 8 & 681.25 & 7.5 & $\begin{array}{l}\text { Chlorophyll } \\
\text { fluorescence }\end{array}$ \\
\hline 9 & 705 & 10 & $\begin{array}{l}\text { Atmospheric correction, } \\
\text { red edge }\end{array}$ \\
\hline 10 & 753.75 & 7.5 & $\begin{array}{l}\text { Oxygen absorption } \\
\text { reference }\end{array}$ \\
\hline 11 & 760 & 2.5 & Oxygen absorption \\
\hline 12 & 765 & 5 & Oxygen absorption \\
\hline 13 & 775 & 15 & Aerosols, vegetation \\
\hline 14 & 865 & 20 & $\begin{array}{l}\text { Aerosols correction } \\
\text { over the ocean }\end{array}$ \\
\hline 15 & 890 & 10 & $\begin{array}{l}\text { Water vapor absorption } \\
\text { reference }\end{array}$ \\
\hline 16 & 900 & 10 & Water vapor absorption \\
\hline
\end{tabular}

studies only, as the on-board data recording capacity is insufficient to capture all the data at this resolution on a global scale. Table 8 gives some indication of the types of information that will be derived from the various MERIS bands (see also Rast ${ }^{(10)}$ ). As with MODIS, particular care has been taken with the calibration systems for MERIS to ensure high quality of data.

\subsection{Algorithms, Including Atmospheric Correction}

As noted earlier (section 2), the critical measurement made by an ocean color sensor is the value of the waterleaving radiance $L_{\mathrm{w}}$ in each band in which the sensor measures. These measurements can then be related to the in-water biological constituents that are of interest to the biological oceanographer. The standard algorithms used to produce the global CZCS chlorophyll (pigment) concentration data set that is now widely available ${ }^{(6)}$ are given by McClain et al. ${ }^{(29)}$ They are empirical algorithms that take into account the changes in the chlorophyll concentration. Thus the satellite-determined chlorophyll concentration $C_{\text {sat }}$ is given by Equations (5) and (6)

$$
\begin{aligned}
C_{\mathrm{sat}}= & 1.13\left[\frac{L_{\mathrm{w}}(443)}{L_{\mathrm{w}}(550)}\right]^{-1.71} \\
& \text { for } 0<C_{\mathrm{sat}}<1.5 \mathrm{mg} \mathrm{m}^{-3}
\end{aligned}
$$


and

$$
\begin{aligned}
C_{\mathrm{sat}}= & 3.33\left[\frac{L_{\mathrm{w}}(520)}{L_{\mathrm{w}}(550)}\right]^{-2.44} \\
& \text { for } 1.5 \mathrm{mg} \mathrm{m}^{-3}<C_{\mathrm{sat}} .
\end{aligned}
$$

The change in algorithm at $C_{\text {sat }}=1.5 \mathrm{mg} \mathrm{m}^{-3}$ is necessary as the value of $L_{\mathrm{w}}(443)$ becomes too small to quantify accurately at greater concentrations owing to the digitization and signal-to-noise characteristics of CZCS. The estimation of the near-surface pigment concentration using these algorithms is accurate to within $35 \%$ for Case 1 waters. $^{(6)}$

The above algorithms are based on comparisons of the satellite data with in situ measurements and are therefore empirical in nature. More sophisticated algorithms have been developed for CZCS data that rely on modeling the dependence of the water-leaving radiance on the phytoplankton pigment concentration (for example, the so-called semianalytic model of Gordon et al. ${ }^{(20)}$ ). In addition, regional algorithms have been developed to improve the retrieval of chlorophyll concentration in specific areas (for example, the Southern Ocean)..$^{(30)}$ These types of algorithm have not been applied routinely to CZCS data. The new generation of ocean color sensors, with more bands and improved digitization and $\mathrm{S} / \mathrm{N}$, will allow more sophisticated algorithms to be employed and more, and more accurate, biogeochemical information to be recovered from the data. ${ }^{(9,24)}$

In order to obtain the water-leaving radiance values a simple atmospheric correction algorithm has been applied to the CZCS data set. A standard atmospheric aerosol type was assumed in order to correct for the presence of aerosols in the atmosphere. ${ }^{(6)}$ This correction introduces errors in regions where other types of atmospheric aerosol are present, such as off the north-west African coast, which is affected by Saharan dust. Other atmospheric correction algorithms have been developed and used for specific circumstances, some details of which have been given by Barale and Schlittenhardt. ${ }^{(21)}$ More sophisticated algorithms have been designed for the new generation of ocean color sensors (see, for example, Gordon and Wang $^{(22)}$ for SeaWiFS and Gordon ${ }^{(16)}$ for MODIS). All the algorithms used for ocean color data have to screen the data to eliminate sunglint effects, and some of the more sophisticated algorithms take into account other effects that contribute to the radiances measures by the sensor, such as the presence of whitecaps on the sea surface. It is important to note that as the new generation of ocean color sensors have more radiometric sensitivity than CZCS, this in turn requires a better atmospheric correction algorithm if more accurate measurements of water-leaving radiances are to be made. The extra bands that the new sensors have allow for the atmospheric correction procedure to be much improved over that used for CZCS. ${ }^{(16)}$

The spatial and temporal coverage of the oceans provided by CZCS was patchy. The data have been averaged to provide so-called higher level products, such as weekly and monthly composites. These can be used more easily to study such phenomena as seasonal variations (section 4.1). Thus at Level 1 there are the individual CZCS images, with calibrated radiances, having a spatial resolution of $1 \mathrm{~km}$. At Level 2 there are the derived geophysical parameters for each CZCS images, at a $4 \mathrm{~km}$ spatial resolution, the derived parameters being the phytoplankton pigment concentration, the diffuse attenuation coefficient, normalized water-leaving radiances at 440,520 , and $550 \mathrm{~nm}$, and the aerosol radiance at $670 \mathrm{~nm}$. At Level 3, the data have been binned onto an Earth-grid with about an $18.5-\mathrm{km}$ resolution at the equator. The Level 3 data are available as daily, weekly (5 days) and monthly averages. Full details of these data are given by Feldman et al. ${ }^{(6)}$ SeaWiFS and OCTS data are now becoming available in similar formats over the Internet.

\subsection{Calibration and Validation}

The calibration and validation of spaceborne ocean color sensors is vital if the data obtained are to be used in any quantitative manner, rather than just as images of the sea. Considerable effort has been and will continue to be devoted to the calibration and validation of the data from ocean color sensors. Particular emphasis on the quality of the atmospheric correction applied to the data is necessary, as this has such a large impact on the retrieved water-leaving radiance values that provide the basic input into all the bio-optical algorithms. ${ }^{(8)}$ As noted in the previous subsection, if the improved radiometric sensitivity of the new sensors means that a better atmospheric correction be applied to the data, this in turn will need to be validated. ${ }^{(31)}$

The details of the calibration and validation process are rather involved and so will not be discussed in detail here. There are on-board calibration systems that monitor the performance and stability of the sensor (see, for example, Evans and Gordon ${ }^{(8)}$ for CZCS and Barnes et al. ${ }^{(28)}$ for MODIS). More generally, what are required are accurate measurements of the optical properties of the water and of the atmosphere (particularly with regard to atmospheric aerosols), and of the phytoplankton and associated pigments found in the water. Instruments that can be deployed from both ships and buoys have been developed to make such measurements (see, for example, Clark et al. $\left.{ }^{(31)}\right)$. In addition, measurements of other contributions to the radiance seen by the satellite sensor, such as that due to whitecaps, need to be made. Even if such measurement techniques are available, care 
must be taken to make measurements across a range of conditions for the calibration and validation process to be successful and useful. A further consideration is the temporal and spatial sampling of the in situ measurements compared with those made by the satellite. Clearly a ship can survey only a small part of an area that the satellite can see instantaneously, and in the time it takes to carry out the survey conditions may have changed (for example, owing to the currents advecting the phytoplankton around). Similarly how representative are data measured by a buoy at a single point, compared with the typical 1-km square pixel measurement obtained by the satellite, given the spatial variability of the phytoplankton?

The end-result of the calibration and validation efforts for the CZCS global data set was that the accuracy of the pigment concentration retrieval was shown to be $35 \%$ in Case 1 waters, and within a factor of two otherwise. ${ }^{(6)}$ The aim for SeaWiFS is to obtain water-leaving radiances to within $5 \%$ and chlorophyll-a concentration to within $35 \%$ across the range $0.05-50 \mathrm{mg} \mathrm{m}^{-3}$. ${ }^{(25)}$ To achieve this a comprehensive calibration and validation plan has been adopted. ${ }^{(32)}$ Similar procedures are being adopted for the other ocean color missions ${ }^{(31)}$ and should provide well-calibrated data for use in scientific studies.

\section{APPLICATIONS}

The previous sections have given some indication of the complexity of obtaining biological information from remotely sensed ocean color measurements from space. In this section the focus will be on how such measurements may be used to improve our understanding of biological oceanography. All the examples that will be discussed rely on the use of CZCS data. Although OCTS and SeaWiFS have provided and are providing new ocean color data (see section 2), little has yet appeared in the open literature on the application of these data to the study of ocean biology. In addition to scientific applications of the data, which will be the main focus of this section, the commercial applications of the data will also be briefly discussed, as will potential future scientific applications of data from the new generation of ocean color sensors (MODIS, MERIS).

Before proceeding it is useful to define and discuss a number of terms that will be used in this applications sections. ${ }^{(5,13,17)}$ The growth of phytoplankton in the upper layers of the ocean is controlled by the availability of sunlight and nutrients (such as nitrate, silicate, phosphate, and iron) and by predation (the algae being eaten by zooplankton). In general, the phytoplankton may be regarded as passively advected by the turbulent flow in the ocean surface layer, the so-called mixed layer. A phytoplankton bloom occurs when the factors affecting growth are such that rapid growth can occur. For example, blooms may be caused by the injection of nutrients into the mixed layer due to the presence of a cyclonic eddy, which causes local upwelling of nutrient-rich water. ${ }^{(33)}$ The spring bloom occurs in certain parts of the ocean (for example the North Atlantic Ocean) when the mixed layer, deepened by the effects of winter storms, begins to shallow as the ocean begins to heat up in the spring (a process known as restratification). The mixing down of the layer in winter has entrained fresh nutrients into the layer. It has also reduced phytoplankton growth as the phytoplankton have been mixed down by the turbulence in the layer away from the euphotic zone. The shallowing of the layer in spring means that the phytoplankton spend more time in the euphotic zone, allowing them to grow rapidly (abundant sunlight and nutrients). At this stage predation is low because zooplankton numbers are low, so phytoplankton growth outstrips zooplankton grazing and a bloom occurs. As the zooplankton begin to grow rapidly and grazing increases, and the phytoplankton use up the nutrients in the mixed layer, growth begins to slow and then the numbers decay owing to mortality and predation. The zooplankton numbers then decrease (owing to lack of food) and by late summer the bloom has finished. This cycle is repeated each year. Various variations of this cycle are possible, but will not be discussed here (see, for example, Mann and Lazier ${ }^{(5)}$ and Longhurst $\left.{ }^{(17)}\right)$. Regions of the ocean that have low concentrations of the nutrients required for phytoplankton growth are called oligotrophic, while those that have high nutrient concentrations are called eutrophic. Many of the nutrients necessary for phytoplankton growth (such as $\mathrm{CO}_{2}$ ) are available in the ocean in sufficient quantities not to limit growth. The key nutrients necessary for phytoplankton growth that may only be available in low concentrations, and therefore limit growth, are nitrate, silicate, and phosphate (sometimes called macronutrients). In addition, small quantities of so-called micronutrients (trace elements such as iron) are also necessary for the growth of some species of phytoplankton. Ocean areas where phytoplankton growth is limited by lack of iron or some other process (such as grazing by zooplankton), but that have an abundance of the macronutrients are called high nitrate (or nutrient) low chlorophyll (HNLC) areas.

\subsection{Measurements of Phytoplankton}

As noted in the introduction, the primary component of the biology about which information is obtained from measurements of ocean color is phytoplankton. In this subsection three particular applications of ocean color relating to phytoplankton directly will be considered: measurement of chlorophyll and related pigments, of 
primary production, and of coccolithophores (a particular type of phytoplankton). The examples discussed are illustrative rather than comprehensive; other information may be found in the reviews of Abbott and Chelton ${ }^{(34)}$ and Aiken et al. ${ }^{(24)}$

\subsubsection{Chlorophyll and Other Pigments}

As discussed earlier (section 2) ocean color measurements give information about the phytoplankton present in the near-surface layers of the ocean due to the presence of chlorophyll-a and other pigments necessary for photosynthesis in the phytoplankton and to associated colored degradation products from the phytoplankton. Thus the basic information provided from the ocean color sensor is a measure of the surface concentration of chlorophyll-a and associated pigments. Relating this concentration to the phytoplankton is a nontrivial exercise, ${ }^{(11)}$ but the satellite chlorophyll concentration measurements in themselves have provided a unique insight into the global biological behavior of the oceans.

Perhaps the simplest observation that has been made has arisen from producing seasonal (spring, summer, autumn, winter) pictures of the global chlorophyll concentrations derived from CZCS data (see, for example, McClain et al. ${ }^{(29)}$ and Figure 1). These pictures show: (1) the occurrence of the spring bloom in the North Atlantic, (2) the relatively constant biological behavior of the Southern Ocean, (3) the low-concentration (desert-like) regions of the subtropical gyres, (4) the high concentrations in the Arabian Sea during the summer monsoon, and (5) the higher concentrations in the northern and tropical Atlantic compared with equivalent regions of the Pacific Ocean. The reasons for these phenomena are related to the ocean physics and will be discussed below (section 4.3). The point to note here is that, while these phenomena had been observed previously from scattered ship-based observations, CZCS data on chlorophyll concentrations provided the first global and spatially coherent view of them.

Yoder et al. ${ }^{(35)}$ have used the monthly CZCS chlorophyll concentration values to look at the biological seasonal cycle in the oceans on a global scale. They averaged the data spatial into latitude bands, defining an equatorial band and northern and southern hemisphere subtropical and subpolar bands. Despite some problems associated with the coverage available from CZCS data, fewer data having been acquired in the southern hemisphere than in the northern, they were able to compare the seasonal changes in the chlorophyll concentration for the Atlantic, Pacific, and Indian Oceans in the appropriate latitude bands. They found that the coverage of the equatorial Atlantic Ocean was poor and concluded that the annual cycle, with a maximum in
December, may not be representative. For the equatorial Pacific Ocean they found no seasonal cycle, while for the equatorial Indian Ocean they concluded that the maximum in August/September is related to the subtropical monsoon cycle there. For the subtropical Atlantic and Pacific Oceans, they found that the seasonal cycles are similar, with the winter chlorophyll concentrations approximately double those of the summer. This pattern was attributed to the higher nutrient flux into the mixed layer in winter and the relatively high solar irradiance during winter (compared with higher latitudes). The subtropical northern Indian Ocean was found to be anomalous, with the highest chlorophyll concentrations in the summer months. This was explained by the upwelling of nutrient-rich waters during the summer monsoon. For the subpolar waters of the North Pacific and North Atlantic Oceans they found the existence of the spring bloom, which was more pronounced in the North Atlantic Ocean. This bloom is the result of the increase in solar irradiance in the spring, the shallowing of the mixed layer (due to solar heating and restratification) and the corresponding growth in phytoplankton. This growth outstrips the zooplankton grazing rate initially, but by late spring or summer the phytoplankton losses are greater than their growth and the bloom declines. The subpolar waters of the southern hemisphere were found not to exhibit this pattern. This hemispherical asymmetry may be due to differences in micronutrient (iron) availability, solar irradiance, vertical mixing, or zooplankton grazing. Overall, the seasonal patterns found by Yoder et al. ${ }^{(35)}$ are consistent with predictions based on simple models of predator-prey (zooplankton-phytoplankton) interactions with implicit assumptions about growth limitation by nutrients and solar irradiance. In some respects this agreement is surprising as there is considerable spatial and temporal variability in the distribution of phytoplankton (section 4.3). Therefore the averaging procedure used ${ }^{(35)}$ might have suppressed or distorted any seasonal signal, which it has not. Instead, their results confirm on the large scale a picture of the seasonal behavior of the phytoplankton that was arrived at originally from a more limited set of in situ observations. Banse and English ${ }^{(36)}$ have given a complementary view of seasonal cycles which focuses more on specific areas and considers interannual variability. Their results are in broad agreement with those of Yoder et al., ${ }^{(35)}$ but show more regional detail as they did not use latitudinal averaging.

Moving from the global to a more regional scale, Sullivan et al. ${ }^{(30)}$ have studied the distribution of phytoplankton blooms in the Southern Ocean (south of $30^{\circ} \mathrm{S}$ ) using CZCS data, a region poorly sampled by traditional ship-based measurements. They derived a regional pigment retrieval algorithm to improve the estimation of chlorophyll concentration from the CZCS data. 
(a)
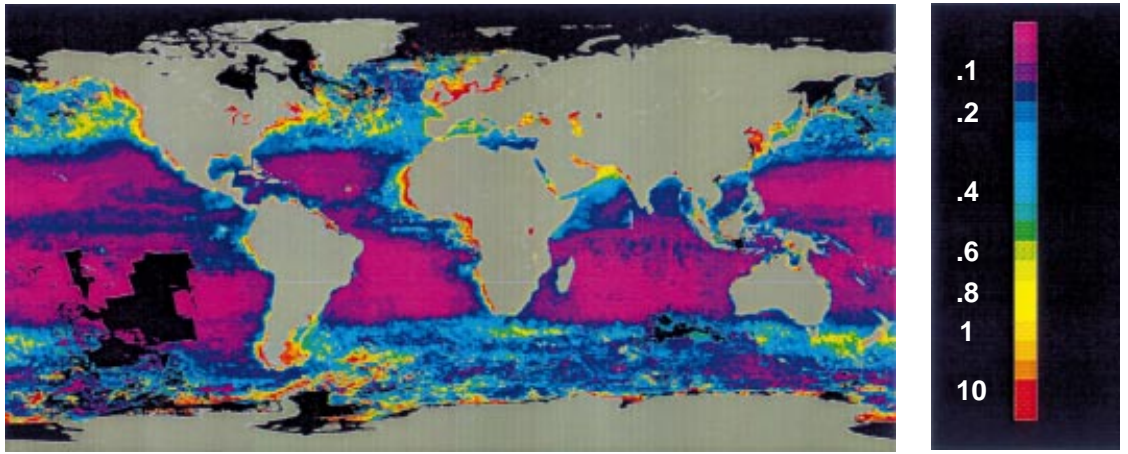

(b)
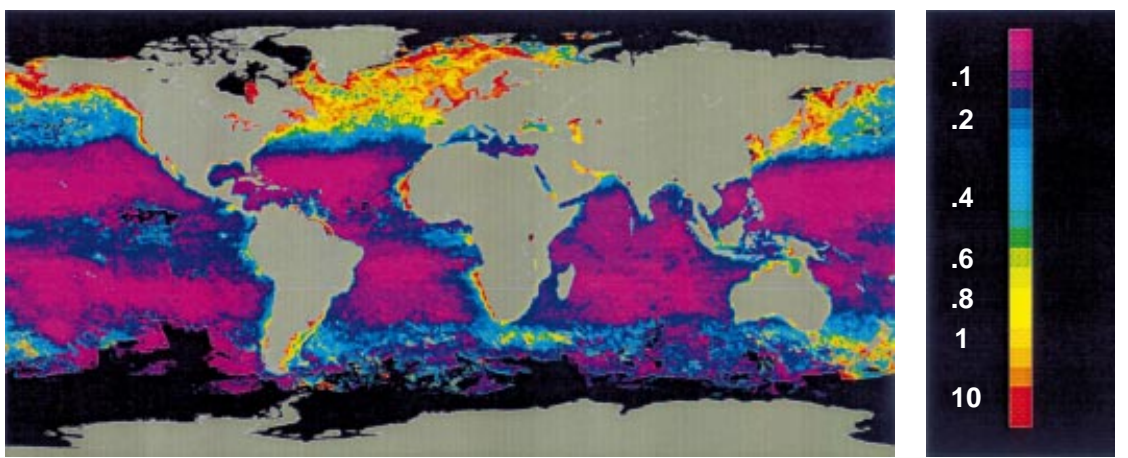

(c)
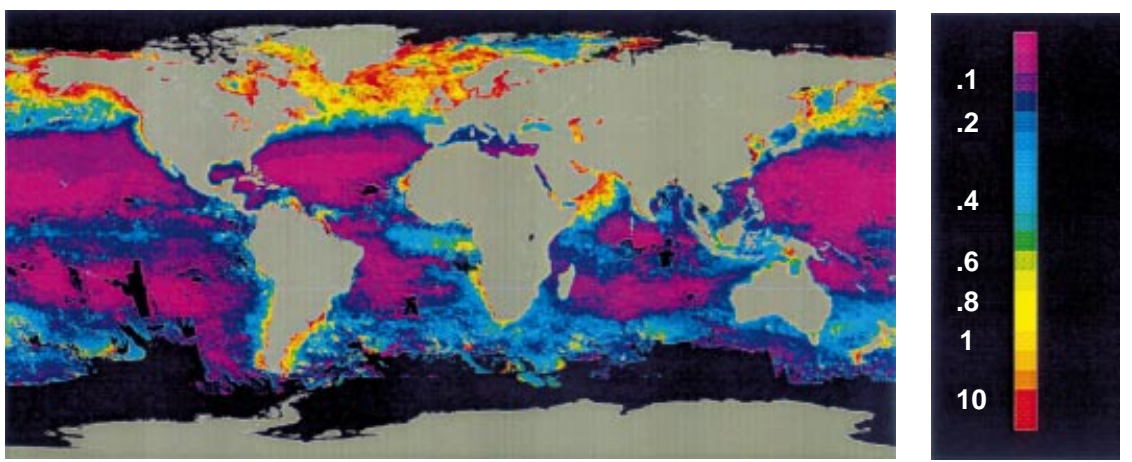

(d)
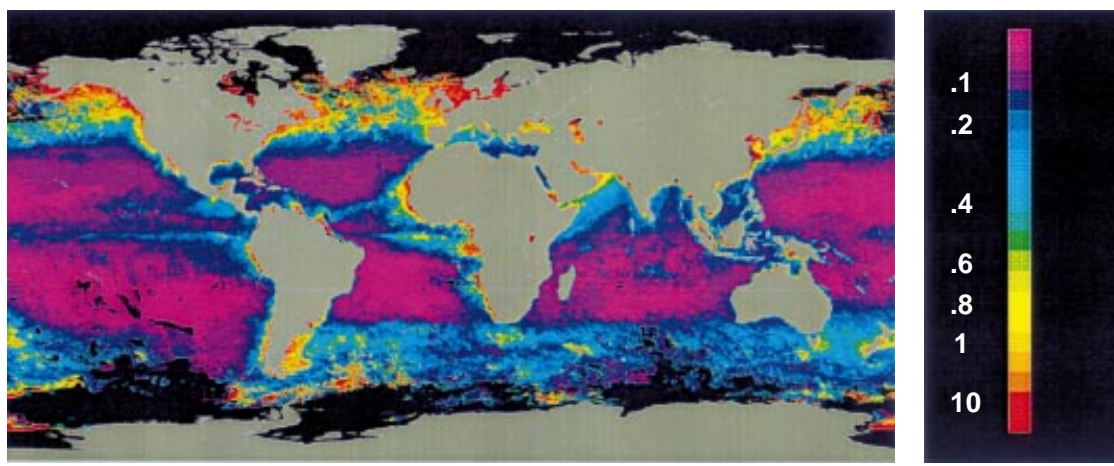

Figure 1 (a) CZCS seasonal sea surface chlorophyll distribution for the northern hemisphere winter months, using data from 1979

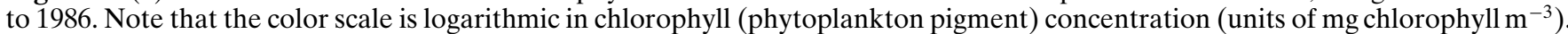
Data provided by NASA/Goddard Space Flight Center. (b) As for (a) but for northern hemisphere spring. (c) As for (a) but for northern hemisphere summer. (d) As for (a) but for northern hemisphere autumn. Note the following features of the data shown in the figure: (i) the bloom of phytoplankton (yellow/orange/red) in the North Atlantic Ocean during the northern hemisphere spring, (ii) the bloom of phytoplankton (yellow/orange/red) in the Arabian Sea during the summer monsoon, (iii) the "desert" regions, low phytoplankton (purple), in the subtropical gyres, (iv) black indicates missing data. Even using data from 1979 to 1986 gaps exist in the CZCS data record (see section 3.1.1), (v) the data are illustrative of results discussed in sections 4.1.1 and 4.3.1. 
They found that blooms were localized to three regions: (1) in shallower waters (near continental margins, islands, and over shoals), (2) in coastal polynyas of the Antarctic sea ice zone, and (3) downstream of the continents (South America, Africa, Australia plus New Zealand) that interrupt the flow of the major circumpolar currents. In relation to the blooms downstream of the continents, they conclude that transport of iron (thought to be the limiting micronutrient in the Southern Ocean) from the adjacent continental shelves stimulates and sustains these blooms. They provide evidence of latitudinal banding of the chlorophyll concentration around the Antarctic continent and link this to the physical processes that occur there. The results obtained ${ }^{(30)}$ are now being used in conjunction with other observations to study the ecology of the Southern Ocean. ${ }^{(37)}$ This shows that the CZCS data are both of intrinsic interest and of value in gaining a better understanding of the ecology of the oceans, in combination with other data. This points the way forward for the use of the new ocean color data that are being and that will be acquired.

Many other examples of the use of chlorophyll concentration data from CZCS could be given; the ones given have been chosen to illustrate the unique value of remotely sensed ocean color data and their potential for understanding the biology of the oceans.

\subsubsection{Primary Production}

Phytoplankton are the main primary producers of the upper ocean, in that they convert inorganic compounds (nutrients, such as nitrate and silicate) into organic compounds through photosynthesis. This is the beginning of the oceanic food chain and the amount of organic material (biomass) produced is known as the primary production. ${ }^{(13)}$ The rate at which biomass is produced is known as the primary productivity. The net primary production takes into account losses due to respiration and is the amount of photosynthetically fixed carbon available to the next level in the food chain. ${ }^{(38)}$ The primary production may further be subdivided into new and regenerated components. New production is that based on new nutrients that have entered the euphotic zone, while regenerated production is that which occurs due to the recycling of nutrients there (through processes such as microbial breakdown of dead organic matter and fecal pellets). The ratio of new to total primary production is known as the $f$-ratio. ${ }^{(39)}$ Understanding the oceanic primary production is important for the carbon cycle and the $\mathrm{CO}_{2}$ problem (see section 4.2). It is also important in terms of assessing the sustainability of the global fisheries, ${ }^{(40)}$ an increasingly vital issue given the increasing world population's requirements for food.

In order to estimate primary production it is necessary to have not only the surface chlorophyll information from ocean color data, but also information about the photosynthesis-light relationship and possibly the structure of the chlorophyll distribution in the vertical. Here two recent attempts to estimate the primary production of the oceans from CZCS data are described, those of Longhurst et al. ${ }^{(39)}$ and Field et al. ${ }^{(38)}$ References to earlier attempts may be found in these papers.

Longhurst et al. ${ }^{(39)}$ use chlorophyll estimates from CZCS and an approach developed by Platt and Sathyendranath ${ }^{(41)}$ to calculate primary production. They divide the ocean up into a number of biogeochemical provinces, based on in situ and satellite data, in order to specify the spatial and temporal variability of the parameters that are needed by their algorithm for primary production. The provinces are an attempt to characterize the biological, chemical, and physical variability of the oceans. As well as the surface chlorophyll value from CZCS, their algorithm requires information about the depth of the chlorophyll maximum, the standard deviation around the peak value, and the ratio of the chlorophyll peak at its maximum to the total peak biomass. The latter information is compiled from an extensive database of ship-based observations. From this information a vertical chlorophyll profile is constructed at each point on a global $1^{\circ}$ grid on a quarterly basis (centered on the 15 th day of January, April, July, and October). The calculations were restricted to a quarterly basis owing to the sparsity of in situ measurements available. Surface radiation was computed from the sun angle and climatological information from cloud cover. This was combined with experimentally derived information on the photosynthesis-light relationship, representing polar, westerlies, trade-wind, and coastal domains, to calculate the total primary production. The calculation makes no allowance for the presence of suspended sediments in coastal waters for which the CZCS chlorophyll algorithm is inadequate and which will affect the estimates obtained. Taking this and other uncertainties into account and integrating over the year, Longhurst et al. ${ }^{(39)}$ estimate the annual primary production as 44.7-50.24 Gt C per year (1 Gt C is one Gigatonne of carbon $=1 \mathrm{Pg} \mathrm{C}$, one Petagram of carbon $=10^{15} \mathrm{~g}$ of carbon). They found that this figure is in reasonable agreement with extrapolations based on a few good in situ measurements.

Field et al. ${ }^{(38)}$ calculated the net primary production for both oceanic and terrestrial biospheres. For the ocean they used a depth integrated model, which requires information about the surface chlorophyll concentration, the depth of the euphotic zone, PAR, and a temperaturedependent maximum chlorophyll-specific carbon fixation rate (the amount of biomass measured in carbon per unit chlorophyll per day). The temperature field is also obtained from satellite data (from AVHRR), as is the solar irradiance (from Bishop and Rossow ${ }^{(42)}$ ). 
This model is based on the work of Behrenfeld and Falkowski, ${ }^{(43)}$ who suggest that the improvement gained by using a vertically resolved model, such as that of Longhurst et al., ${ }^{(39)}$ is negligible compared with using a depth-integrated model. Their resulting estimate of global net primary production is $48.5 \mathrm{GtC}$ per year, which lies in the middle of the range calculated by Longhurst et al. ${ }^{(39)}$ It is interesting to note that while the production is of the order of $50 \mathrm{Gt} \mathrm{C}$ per year, the actual phytoplankton biomass is only ca. $1 \mathrm{GtC}$. This implies that the phytoplankton biomass turns over approximately once per week on average. ${ }^{(44)}$ This is consistent with the fact that the phytoplankton lifecycle is relatively short, of the order of a day.

Prior to the availability of ocean color data, estimates of global primary production were more difficult to obtain. ${ }^{(39,44)}$ Both of the approaches discussed above rely on more than just the satellite data to obtain these estimates. Neither method is able to distinguish between new and regenerated production, which it is necessary to do in studying carbon fluxes into the ocean (section 4.2). However, Sathyendranath et al. ${ }^{(45)}$ have proposed a method for doing this using satellite data (see section 4.2 below). Algorithms for estimating primary production are being developed for MODIS. ${ }^{(9)}$

\subsubsection{Coccolithophores}

Coccolithophores are phytoplankton that form external calcium carbonate $\mathrm{CaCO}_{3}$ scales called coccoliths, which are a few micrometers in diameter and ca. 250-750 nm in thickness. These can form multiple layers, which eventually detach and sink to the sea floor. Coccolithophores are also one of the principal producers of dimethyl sulfide (DMS). ${ }^{(4)}$ Their importance is probably greatest during a bloom, where their concentrations can reach up to 115 million cells per liter. ${ }^{(47)}$ The most abundant of the species is Emiliania huxleyi, which can be found throughout most of the world's oceans, with the exception of the polar oceans. ${ }^{(48)}$ They can be detected in satellite imagery because the presence of the coccoliths leads to high reflectance in the surface waters due to their intense scattering of light. ${ }^{(47)}$ Essentially they act like small mirrors suspended in the water and cause a significant portion of the incoming light to be reflected back out from the water.

Whereas phytoplankton pigments change the waterleaving radiance differential across the spectrum owing to absorption, coccolithophore blooms tend to increase the radiance uniformly owing to scattering. ${ }^{(9)}$ The resulting appearance of the ocean can be milky, which is how these blooms were first observed by eye. A consequence of this is that coccolithophore blooms can be detected using the visible channels of the AVHRR, which are not sensitive enough for studying other changes in ocean color. ${ }^{(48)}$ Another consequence is that, in the case of ocean color sensors, a different algorithm needs to be used to estimate their abundance from satellite data. ${ }^{(47)}$ It also means that it is possible to monitor one specific species of phytoplankton, whereas the standard chlorophyll measurements obtained from ocean color do not allow discrimination between different species of phytoplankton. Two effects of the presence of large numbers of coccoliths in the water are first, an increase in the ocean's albedo, and, second, a shading effect that reduces the light level in deeper water (while the scattering of photons increases the light level in the surface waters). These effects have not been studied using satellite data to date (1999).

The most comprehensive study of coccolithophore blooms in the global ocean using ocean color data, from CZCS, is that of Brown and Yoder. ${ }^{(4)}$ They mapped the distribution of blooms using CZCS five-day composite normalized water-leaving radiance data from 1978 to 1986 . The data used have a spatial resolution of $20 \mathrm{~km}$. An automatic spectral classification scheme was used to detect the blooms, based on the spectral characteristics that have been obtained from in situ measurements. Monthly and annual composites were calculated from the five-day composite analyses. They found that coccolithophore blooms annually covered an average area of $1.4 \times 10^{6} \mathrm{~km}^{2}$ of the global ocean from 1979 to 1985 . This represents ca. $0.5 \%$ of the ocean surface. Blooms were most extensive in the subarctic North Atlantic Ocean, annually covering an area of $10^{5} \mathrm{~km}^{2}$ (approximately equivalent to the size of England). As the scattering of light is due to the presence of coccoliths in the water, rather than of the cells themselves, the results are biased towards the declining stage of the blooms when the proportion of coccoliths to cells is greatest. Based on these results they were able to make estimates of $\mathrm{CaCO}_{3}$ and DMS production, using further assumptions regarding the depth of the mixed layer and the concentrations of cells and related chemicals within it. They concluded that on a regional scale the blooms are a significant source of $\mathrm{CaCO}_{3}$ and DMS. In contrast, on a global scale, the blooms detected in CZCS imagery play only a minor role in the production of $\mathrm{CaCO}_{3}$ and DMS and their flux from the mixed layer to deeper waters and to the atmosphere, respectively.

\subsection{The $\mathrm{CO}_{2}$ Problem}

Phytoplankton live in the surface sunlit waters of the ocean. When they grow and reproduce, they absorb carbon dioxide and other chemicals (nutrients) from the water. When phytoplankton blooms occur, the surface waters become depleted in $\mathrm{CO}_{2}$. This induces an 
imbalance between the atmosphere and ocean that allows the ocean to absorb $\mathrm{CO}_{2}$ from the atmosphere. Most of the $\mathrm{CO}_{2}$ removal is not permanent. Approximately $90 \%$ of the phytoplankton die and are decomposed in the surface waters rereleasing their $\mathrm{CO}_{2}$. The remaining fraction (ca.10\%) sinks down into the deeper ocean where it remains out of contact with the atmosphere for long periods of time (as much as 1000 years). A very small fraction $(\ll 1 \%)$ reaches the sea floor where it becomes part of the sea floor sediments and is therefore totally removed from the system (on timescales shorter than geological ones, that is millions of years). ${ }^{(49)}$ Ocean color measurements have been used to look at two parts of this process, the transfer of gases between atmosphere and ocean, and the so-called biological pump that removes the $\mathrm{CO}_{2}$ to the deep ocean and sediments.

\subsubsection{Air-Sea Gas Transfer}

The air-sea transfer of gases is dependent on many complex processes including wave breaking, the production of droplets and spray, the entrainment of air bubbles into the water and their subsequent behavior, and the presence or absence of surfactants. Clearly this complexity is too difficult to model in all its aspects. Therefore the net air-sea flux of $\mathrm{CO}_{2}$ is usually parameterized in terms of a wind speed-dependent gas exchange coefficient multiplied by the difference in the partial pressure of $\mathrm{CO}_{2}$ $\left(p \mathrm{CO}_{2}\right)$ in the air and in the water. ${ }^{(50)}$ The presence of phytoplankton in the surface waters of the ocean, which use the $\mathrm{CO}_{2}$ for photosynthesis, decreases the $p \mathrm{CO}_{2}$ of the surface waters allowing greater uptake of $\mathrm{CO}_{2}$ from the atmosphere. At the present time the potential feedback (whether positive or negative) between changes in climate (increasing atmospheric $\mathrm{CO}_{2}$ ) and the phytoplankton are not understood. ${ }^{(1)}$

In situ measurements in the North Atlantic Ocean ${ }^{(51)}$ have shown that the spatial variability of the oceanic $p \mathrm{CO}_{2}$ is correlated with the spatial variability of the SST and chlorophyll concentration. These results were obtained in the springtime, during the bloom period. Watson et al. ${ }^{(51)}$ suggest that using satellite-derived SST and chlorophyll values may allow the determination of the $p \mathrm{CO}_{2}$ value. Subsequent modeling studies by Antoine and Morel ${ }^{(52)}$ (see also Antoine and Morel $^{(53)}$ ) have shown that the relationship between $p \mathrm{CO}_{2}$, SST, and chlorophyll varies spatially and temporally, but may be sufficiently stable on a seasonal basis to make a $p \mathrm{CO}_{2}$ estimate based on satellite data. To date (1999) this does not appear to have been done.

However, a related study has been carried out by Erickson and Eaton, ${ }^{(54)}$ who studied the flux of carbonyl sulfide from ocean to atmosphere, using CZCS data and an ocean general circulation model. The CZCS chlorophyll data are related empirically to the maximum potential carbonyl sulfide concentration in the surface ocean. The assumption is that the chlorophyll data are representative of the maximum supply of organosulfur compounds that are available for photooxidation. The maximum potential concentration is then related to the actual concentration taking account of the surface radiation field of the ocean. Using an appropriate gas transfer coefficient (see above and Liss and Merlivat ${ }^{(55)}$ ) and information on surface radiation, the wind field, and SST, Erickson and Eaton ${ }^{(54)}$ calculate the gas flux for a five-year period, with a $2.8^{\circ}$ spatial resolution, and a 24-hour temporal resolution. Computed values of surface concentrations of carbonyl sulfide are said to agree with experimental data on a regional basis to within the uncertainties of the calculation. They found two orders of magnitude variation in the spatial and temporal gas flux, with the comment that the technique is potentially extendible to other biogeochemically important gases, such as $\mathrm{CO}_{2}$.

To conclude this section, it is worth noting that the gas transfer coefficient itself may be estimated from satellite scatterometer or passive microwave radiometer data on the oceanic wind field. Etcheto et al. ${ }^{(56)}$ have used passive microwave radiometer wind speed data and the Liss and Merlivat ${ }^{(55)}$ formulation of the transfer coefficient's dependence on wind speed to do this. They show that the seasonal variations are large and need to accounted for in calculating the flux of $\mathrm{CO}_{2}$. Together with satellitebased SST and chlorophyll measurements, this provides the basis for global calculation of the air-sea flux of $\mathrm{CO}_{2}$ and other biogeochemically important gases.

\subsubsection{Biological Pump}

The biological pump refers to the process by which part of the of the primary production is removed from the surface layers of the ocean to the ocean interior, as sinking organic particles and as dissolved organic matter. Thus the biological pump reduces the carbon in the surface layers of the ocean (and consequently the $\mathrm{CO}_{2}$ in the atmosphere) and increases the carbon content of the ocean interior, a small fraction of which becomes sediment on the ocean floor. ${ }^{(1)}$ If the processes controlling the primary production were in a steady state, the export production (that part of the primary production lost from the surface layers) would be equal to the new production due to nutrients entering the upper layers of the ocean (section 4.1.2). Thus knowledge of the $f$-ratio (new-tototal production) should give some information about the behavior of the biological pump. ${ }^{(57)}$ The estimation of the $f$-ratio, or equivalently the new and total production, from satellite data has been carried out by Sathyendranath et al. ${ }^{(45)}$ for the Georges Bank area. Using AVHRR SST data, they derived the $f$-ratio using relationships 
between temperature, nitrate, and the $f$-ratio based on in situ measurements. Combining this with estimates of primary production from CZCS data, they were able to estimate new production. Such an approach may provide information on the biological pump, but the assumption that the processes controlling primary production may be regarded as in a steady state has been questioned. ${ }^{(44)}$ Storms, eddies, El Niño, and other transient physical processes affect the delivery of nutrients to the ocean's surface layers (see section 4.3). On short timescales (up to interannual ones) a steady state cannot be assumed. Over longer timescales an approximate steady-state situation may exist. The processes involved are too complex to be understood using only limited observations (such as SST and ocean color from satellites and some in situ data) and the best way to study them is probably through combining the observations with biophysical models (see section 4.4). Empirical algorithms for estimating new, export, and primary production are being developed for use with MODIS. ${ }^{(9)}$

\subsection{Biophysical Interactions}

It is well known that the biology in the oceans is influenced by the physical and chemical processes occurring there. ${ }^{(5,17)}$ These processes occur across the whole range of time- and space-scales present in the ocean, therefore biological distributions in the sea are patchy on a variety of spatial and temporal scales. ${ }^{(58)}$ This patchiness results from interactions between physical and biological factors with the dominant forcing functions changing with scale. Physical circulation dominates basin scale variability and sets the overall context within which biological distributions are correlated to water masses. At the mesoscale, variability is dominated by fronts and eddies ${ }^{(59,60)}$ and at scales below this, variability becomes a function of biological behavior interacting with physical processes such as turbulence and mixing. ${ }^{(61,62)}$ Clearly it is not possible to study the microscale processes, involving turbulence and mixing, with a satellite sensor that has a spatial resolution of ca. $1 \mathrm{~km}$. However, it has proved possible to gain insight into the large scale (gyre scale, $\mathrm{O}(1000 \mathrm{~km})$ ) and mesoscale processes $(\mathrm{O}(10-200 \mathrm{~km}))$ and these are discussed in the next two subsections.

\subsubsection{Large Scale}

The links between the large-scale $\mathrm{O}(1000 \mathrm{~km})$ physical structure of the ocean and its biology has been understood for some time on the basis of in situ measurements made from ships and by using simple models (see, for example, Sverdrup ${ }^{(63)}$ and Mann and Lazier $\left.{ }^{(5)}\right)$. However, as noted by Longhurst, ${ }^{(17)}$ the distribution of phytoplankton in the ocean was only known in broad terms, while CZCS ocean color data revealed novel information about the global seasonal distribution (see section 4.1.1), despite the fact that CZCS could not directly detect the presence of deep chlorophyll maxima. The basic latitudinal variation in phytoplankton production is due to the decrease in light available for photosynthesis from the equator to the poles and the (inverse) increase in wind mixing which brings nutrients into the surface layers. Both these effects vary seasonally. The ability of the wind mixing to bring nutrients into the surface waters is affected by the degree of stratification (variation of the density gradient with depth) of the ocean. Superimposed on this rather simple picture are the effects of the large-scale ocean currents and gyre circulations, which modify the basic latitudinal variations (Figure 1; see Mann and Lazier ${ }^{(5)}$ and Longhurst ${ }^{(17)}$ for more detail).

A description of the physical effects leading to the spring bloom in the North Atlantic (north of ca. $40^{\circ} \mathrm{N}$ ) has been given above (see the beginning of the section), and this bloom has been observed in CZCS data. ${ }^{(17,29)}$ It has proved possible to relate the northward progression of the bloom during the spring and summer, as observed in CZCS data, to the latitudinal decrease in the mixed layer depth and increase in light levels over that part of the year. ${ }^{(21)}$ The North Atlantic Ocean is anomalous in having such a strong spring bloom feature. ${ }^{(17)}$ To the south, the subtropical gyre of the North Atlantic Ocean is oligotrophic, with low levels of phytoplankton, owing to the basic downwelling nature of the flow in the center of the gyre which prevents the supply of new nutrients to the surface layers. This is true of the central gyres of all the oceans, as can be seen from the paper by Falkowski et al. ${ }^{(44)}$ (see also Barale and Schlittenhardt ${ }^{(21)}$ ), who show the seasonal variation of upper ocean chlorophyll concentrations, from CZCS, alongside the large-scale flow derived from satellite altimeter data. These are the so-called "desert" regions in terms of phytoplankton productivity. It can be seen from CZCS data that there are other regions of the ocean that are more productive, but not as much as might be expected. These are the subarctic eastern Pacific Ocean, the eastern equatorial Pacific Ocean and the Southern Ocean. Despite physical processes that supply sufficient macronutrients for high levels of primary production to occur (as is the case in the North Atlantic Ocean), they appear to be limited by the lack of iron (or grazing by zooplankton; see Mann and Lazier $^{(5)}$ and Falkowski et al. $\left.{ }^{(44)}\right)$. These are the HNLC areas of the ocean.

A specific example of the effect of the large-scale ocean physics on the biology is that of the El Niño in the equatorial Pacific. ${ }^{64)}$ This has been studied using CZCS data and a model by Halpern and Feldman. ${ }^{(65)}$ For non-El Niño conditions they found results consistent with the HNLC scenario. They were able to observe a 
reduction in phytoplankton pigment concentration during the 1982-1983 El Niño due to the smaller nitrate flux into the mixed layer, this being the result of the reduction of the upwelling of nutrient-rich waters when El Niño occurs. It was shown that the amplitude of the annual cycle of pigment concentration was small (almost undetectable), whereas the impact of the El Niño (an interannual variation) was substantial. Owing to the sparsity of CZCS data for the region in 1983-1984 they were unable to examine the effect on the biology of the La Niña event that followed the El Niño. The recent El Niño (1997-1998), one of the strongest on record, has been observed by SeaWiFS and this will no doubt in time provide new insights into the impact of the event on the ocean biology.

The growth in computing power since 1990 has meant that more realistic modeling of the physics of the ocean has been possible and also the development of basinscale coupled biophysical models. Using such models it is possible to predict the overall seasonal changes in the phytoplankton in the ocean. CZCS data have provided the means to check whether these predictions are valid on temporal and spatial scales that would not be possible using traditional ship-based measurements. One example is the work of Sarmiento et al. ${ }^{(57)}$ who modeled the North Atlantic $\left(20^{\circ} \mathrm{S}\right.$ to $\left.60^{\circ} \mathrm{N}\right)$ and found that their predictions of the seasonal variations in the surface chlorophyll concentration matched well overall except for some specific regions. For example, the model predicted higher concentrations of chlorophyll along the equator because the model physics leads to too much nutrient being supplied, allowing more phytoplankton growth than is observed. The Sarmiento et al. ${ }^{(57)}$ model did not have the spatial resolution to account for the effects of eddies, which more recent modeling has been able to do. ${ }^{(66)}$ Mesoscale features, such as eddies, can play an important role in the development of the biology and these will be considered next.

\subsubsection{Mesoscale}

For the purposes of this discussion the mesoscale is defined as spatial scales in the range $O(10-200 \mathrm{~km})$. This scale includes such phenomena as eddies, rings, and fronts in the ocean. ${ }^{(5)}$ One effect of the physics on the biology is through horizontal advection, where the currents move the phytoplankton around, and in some situations trap the phytoplankton in discrete patches of water such as a ring or eddy. Another effect is that of the vertical velocities associated with eddies, rings, and fronts. Upward velocities can bring more nutrients into the euphotic zone, allowing the phytoplankton to grow. ${ }^{(33)}$ Downward velocities can move the phytoplankton out of the euphotic zone thus slowing their growth. A secondary effect may be through the influence of the horizontal and vertical currents on the swimming zooplankton that graze the phytoplankton. As numerous studies of mesoscale effects exist (see the review by Abbott and Chelton), ${ }^{(34)}$ only a few examples will be discussed here.

The first example to be considered is that of warm core rings off the east coast of the USA (see Figure 2). These rings form when Gulf Stream meanders are pinched off and trap the warmer Gulf Stream waters in a ring (or eddy). These rings are typically of $\mathrm{O}(100 \mathrm{~km})$ in diameter. Brown et al. ${ }^{(18)}$ describe observations of one such ring using CZCS data and SST data from AVHRR. These observations showed that the ring and the Gulf Stream waters, which were warmer than the surrounding waters, had lower concentrations of pigment during a period when a phytoplankton bloom occurred. GarciaMoliner and Yoder ${ }^{(67)}$ have carried out a more detailed study of pigment concentration in warm core rings in the same region, again using CZCS and AVHRR data. The correspondence between the SST from the AVHRR and the pigment concentration can be seen in the images in their paper. Examining four rings in detail they found that there is decreasing pigment concentration with increasing temperature. They examined a number of hypotheses about the physical processes occurring that affect the biological structure of the ring and conclude that advective entrainment of the surrounding waters at the periphery of the ring is the main factor leading to variability in the pigment concentration. Considerable effort has been devoted to the study of ring processes (see references in Garcia-Moliner and Yoder ${ }^{(67)}$ and Olson ${ }^{(68)}$ ) and ocean color data have contributed to these. Weeks and Shillington ${ }^{(69)}$ looked at CZCS imagery around South Africa and showed an image where the Agulhas current and the rings that spin off from it have lower chlorophyll concentration than the surrounding waters. They found an area of high chlorophyll concentration along the east coast of South Africa, in the Benguela upwelling, which brings nutrient-rich waters up to the surface allowing phytoplankton growth to occur.

An area that has been studied in great detail using CZCS data is the California Current system off the west coast of the USA. Denman and Abbott ${ }^{(70)}$ have studied SST from AVHRR and ocean color from CZCS for the area. They used cross-spectrum analysis to look at the timescales of the evolution of the mesoscale features (particularly upwelling jets and the dynamically less active regions between). They concluded that the patterns of pigment concentration, which they observed in the CZCS data, are controlled by the two-dimensional horizontal mesoscale current field of the upper ocean. They restricted their analysis to horizontal length scales greater than $25 \mathrm{~km}$, and noted that for shorter length scales, biological processes (phytoplankton growth, mortality, sinking, and predation by zooplankton) may be important 


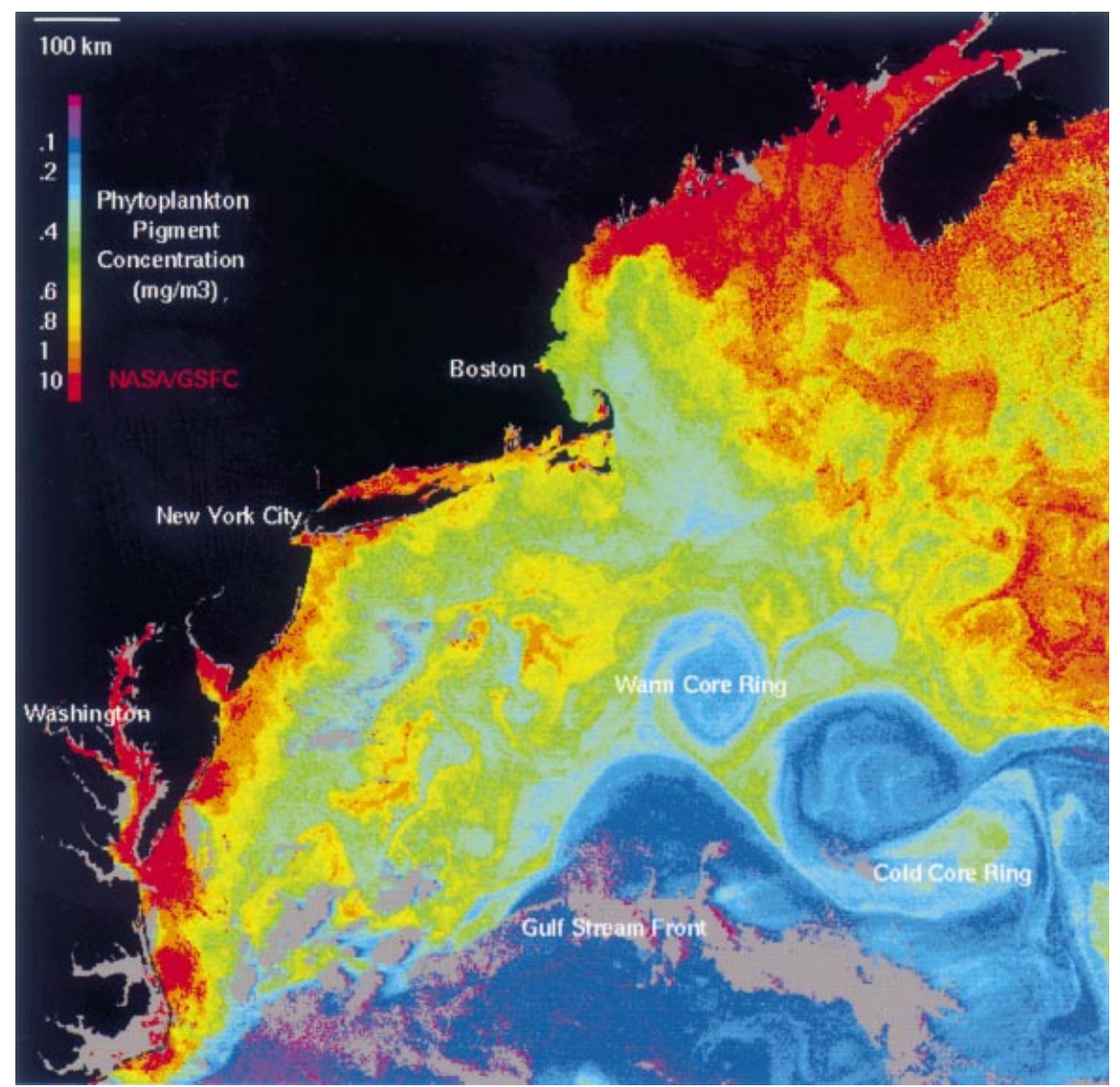

Figure 2 CZCS sea surface chlorophyll (units of $\mathrm{mg}$ chlorophyll $\mathrm{m}^{-3}$ ) image of the east coast of the USA. Clearly visible is the lower productivity water (blue) associated with the warmer waters of the Gulf Stream and with warm core rings shed by the Gulf Stream. The cooler nutrient-rich shelf waters, inshore of the Gulf Stream, show higher productivity (yellow/orange/red). Grey areas denote missing data (primarily due to cloud cover). A variety of mesoscale features - rings, eddies, fronts - can be seen in the image, showing the importance of biophysical interactions for biological productivity. This image is illustrative of the results discussed in section 4.3.2. Data provided by NASA/Goddard Space Flight Center.

for the patterns of patchiness found in the pigment concentrations.

Another example of mesoscale interactions are the filament structures observed in the Portuguese upwelling region by Sousa and Bricaud. ${ }^{(71)}$ The upwelling is driven by local winds and occurs in the period late June to October. CZCS images for the region showed no significant patterns in winter and spring, but during the upwelling period filaments of high chlorophyll concentration were found to extend up to $200 \mathrm{~km}$ off the Portuguese coast. These filaments are related to topographic features, which affect the currents flowing in the region of the Portuguese coast. Sousa and Bricaud ${ }^{(71)}$ also examined the relationship between SST and chlorophyll concentration and found variations consistent with the hypothesis that this relationship depended on the stage of the local upwelling event. The scenario was that initially the upwelled cold nutrient-rich water would have low chlorophyll concentration. This water would be advected offshore while the phytoplankton were growing and SST was increasing. The chlorophyll concentration would then decline as the nutrients were exhausted. Similar behavior had previously been observed off the Californian coast. ${ }^{(72)}$ Upwelling regions are known to be highly productive, owing to the supply of nutrients from the deeper waters and are therefore of considerable biological interest.

A secondary application of ocean color data is that of using the biology to infer dynamical information. This has proved useful in a number of situations, a particular example being the case where, because solar heating of the near surface layer leads to uniform ocean surface temperatures, the SST signal of ocean features has not been visible in the IR satellite data. As the color signal (if it exists) is unaffected by such an effect then dynamical structures, such as eddies, can still be detected despite 
their lack of a SST signature. Thompson and Gower ${ }^{(73)}$ give an example of an eddy near Vancouver Island that was detected by its CZCS ocean color signal, but could not be seen in the IR AVHRR image. Another approach to obtaining dynamical information from ocean color images is that of feature tracking using successive images (see, for example, Garcia and Robinson ${ }^{(74)}$ ). The implicit assumption behind this approach is that the quantity being measured that defines the feature, in this case ocean color, acts as a passive tracer that is simply advected by the ocean currents. As the ocean color is a function of the phytoplankton in the surface waters, a quantity that can be changing rapidly, this assumption is only true on short timescales. Therefore this means of obtaining dynamical information has not been used very much.

\subsubsection{Influence of Biology on the Physics}

In the previous two subsections the influence of ocean physics on the ocean biology has been considered in detail as this is the primary biophysical interaction. However, a secondary interaction is the effect of the presence of phytoplankton on the solar heating of the surface layers of the ocean. ${ }^{(75,76)}$ The presence of phytoplankton can affect the absorption of solar irradiance by the ocean in different way, depending on their concentration and distribution with depth. Ocean color data from CZCS have been used to study this effect for the equatorial Pacific Ocean. ${ }^{(77)}$ Lewis et al. ${ }^{(77)}$ conclude that some of the discrepancies between observed and modeled SSTs for the equatorial Pacific Ocean may be due to the neglect of penetrating solar irradiance in the models. In order to allow for this effect it is necessary to include biology as well as physics in the models. Some recent coupled biophysical models (for example, that of Oschlies and Garcon ${ }^{(66)}$ for the North Atlantic Ocean) take account of this effect.

\subsection{Assimilation of Data into Models}

For many and various reasons, perhaps most importantly understanding the role of the oceans in the carbon cycle and the influence of anthropogenic $\mathrm{CO}_{2}$ emissions into the atmosphere on that cycle, ${ }^{(50)}$ considerable interest exists in developing robust oceanic ecosystem models. ${ }^{(78)}$ By coupling these biological models to physical models of the ocean circulation, the aim is to provide a description, and possibly a prediction, of the contribution of the ocean to global biogeochemical cycles, such as the carbon cycle. ${ }^{(79,80)}$ Another application of the models would be to understand the behavior of the oceanic food chain better, including fisheries. ${ }^{(81)}$

In attempting to carry this out two problems become apparent. First, in contrast to the modeling of the atmosphere or ocean, where a basic description of the physics is provided by the Navier-Stokes equations of fluid dynamics, ${ }^{(82)}$ there is no basic set of equations that describe the ocean ecosystem. Therefore a heuristic approach is generally taken, where sufficient biological components are modeled to describe the problem of interest. ${ }^{(78)}$ For example, a simple three-component (also called a three-compartment) oceanic ecosystem model might include phytoplankton, zooplankton, and nutrients and has been used with a degree of success for some studies. ${ }^{(83)}$ The second problem is related to the first, in that such heuristic models have many parameters that are known to varying degrees of accuracy (for example, the seven-compartment model of Fasham et al. ${ }^{\left({ }^{84}\right)}$ has 27 parameters). This limits the potential applicability of the models, unless the parameters can be better determined. This provides an ideal application for data assimilation in its guise of fitting models to data. ${ }^{(85)}$

Another purpose of data assimilation is that of improving the predictive power of models. This is a familiar application in the context of meteorological forecasting. It is also beginning to be used more widely in the area of physical ocean modeling, but is in its infancy with regard to assimilation of data into biological models. Many techniques have been developed for the assimilation of data into models of atmosphere and ocean physics. ${ }^{(86,87)}$ The applicability of these techniques to oceanic ecosystem models is by no mean automatic and much work remains to be done in this area.

As has been made clear thus far, data assimilation is useful for improving both descriptive and predictive powers of models. However, for this to be possible it is necessary to have good measurements of the biology to assimilate into the ecosystem model. Such measurements exist at a limited number of sites (such as Bermuda), ${ }^{(88)}$ or for particular experiments (such as the North Atlantic Bloom Experiment - NABE) ${ }^{\left({ }^{89}\right)}$ but these may not be representative of what is happening in the ocean basin or on the global scale. The availability of ocean color data from OCTS and from SeaWiFS provides measurements that might help in studying these larger scales. The limitation is that only one component (phytoplankton) of the ecosystem is measured, but in combination with a number of in situ measurements that might be sufficient to improve the models, through data assimilation.

The first person to assimilate data into a coupled biophysical model appears to have been Ishizaka, ${ }^{(90)}$ for the southeastern USA continental shelf area. The data assimilated came from CZCS and the assimilation was of the predictive type. The model was a fourcompartment ecosystem model (nutrient, phytoplankton, zooplankton, detritus), vertically integrated with horizontal advection and eddy diffusion, but with a semiempirical upwelling/downwelling term added. ${ }^{(91)}$ The coupling to the physics is through the advective velocities, which 
Ishizaka $^{(92)}$ obtained from optimally interpolated circulation fields. Ishizaka's assimilation procedure is that of direct insertion, where the phytoplankton values in the model were simply replaced by those estimated from the CZCS ocean color data. Three types of adjustment were applied to the other compartments (nutrient, zooplankton, detritus) to allow for conservation of biomass, and this seemed to make little difference to the results obtained. The model was run forward from the assimilation time and the results compared with CZCS data at later times (comparisons made over a period of a few days). Two cases were considered, one in which the biological interaction and upwelling/downwelling terms were switched off, so that the resulting biological distributions were due purely to the physical advective and diffusive processes, and one where the biological interactions were included. The results suggested that advection dominated in this case, with biological processes acting as a secondary factor. However, the impact of the data assimilation lasted only a few days, indicating the need to assimilate data frequently (every 1-2 days) to keep the model updated and the errors in prediction small. Assimilation of the data had a positive effect overall, but did degrade some aspects of the model (estimates of nutrient fluxes as compared with in situ data). Ishizaka ${ }^{(90)}$ also tested the impact of only assimilating data over part of the region modeled, thus simulating the effect of partially cloudy data. This too seemed to give improved results, though it did cause discontinuities at the boundaries between the areas where data were available for assimilation and where there were none. Direct insertion of data is known to cause problems in the physical model, as the model adjusts by radiation of waves, ${ }^{(86)}$ but this did not appear to cause problems for the advective-diffusive biological model used by Ishizaka. ${ }^{(90)}$ One observation to be made about the study is that the use of a vertically integrated model avoids the issue of how to relate the satellite surface observation of chlorophyll to the subsurface structure in the biology (there being none in this model, as there is no depth dependence). Subsequently, Ishizaka ${ }^{(93)}$ has reported some preliminary results on the use of direct insertion with simpler ecosystem models. He concludes that, ". . . assimilation of phytoplankton data into a simple time-dependent model is not straightforward. Differences in error sources, methods of assimilation, and the timing of the assimilation all result in different model solutions... Furthermore, much more complex ecosystem structure is preferable for the real simulation and this increases uncertainty of the effects of the data assimilation."

Sarmiento et al. ${ }^{(57)}$ compared their results for the seasonal chlorophyll distribution of the Atlantic Ocean, obtained by embedding the Fasham et al. ${ }^{(84)}$ ecosystem model in a ocean general circulation model, with data from CZCS (of the type shown in Figure 1). They found reasonable agreement overall, but some specific discrepancies. Armstrong et al. ${ }^{(94)}$ followed this up by attempting to assimilate CZCS data into the same model at frequencies of 1 and $5 \mathrm{day}^{-1}$. Comparisons improved overall compared with the unforced case of Sarmiento et al., ${ }^{(57)}$ except at high latitudes, with the more frequent forcing giving better results. Sarmiento et al. ${ }^{(51)}$ attributed the discrepancy at high latitudes as being related to the modeling of the zooplankton grazing of the phytoplankton (see their paper for details). They therefore incorporated multiple grazing chains in the model, giving it a total of 13 compartments (nitrate, ammonium, bacteria and dissolved organic nitrogen, plus three compartments each for detritus, phytoplankton, and zooplankton). ${ }^{(94)}$ Assimilation of CZCS data at the same frequencies as before led to much better agreement. The assimilation technique used was "nudging", (86) applied to bring the model chlorophyll values in the upper layer of the model (top $10 \mathrm{~m}$ ) towards the surface observations from CZCS. This procedure requires the model to adjust the subsurface biological distributions and violates the conservation of biomass, which is either added or removed from the model depending on whether the satellite-model difference in chlorophyll is positive or negative. Simplistically one might think that forcing the model values towards the observations would eventually result in complete agreement, but this is not the case owing to deficiencies in the model physics and biology. This is a case of using data assimilation to fit a model to data and thus to improve the model.

The previous two models discussed were twodimensional (horizontal) and three-dimensional in space. A one-dimensional (vertical) model has been developed by Prunet et al. ${ }^{(95)}$ This is a 10-compartment ecosystem model coupled to a one-dimensional mixed layer ${ }^{(95)}$ and the data assimilated are from Station Papa (Station P; $\left.50^{\circ} \mathrm{N}, 145^{\circ} \mathrm{W}\right)$. The difference from the other studies is that Prunet et al. ${ }^{(96)}$ assimilated data into both the biological and the physical components of their model. A variational assimilation technique was used. In their first paper $^{(95)}$ they considered assimilating only surface chlorophyll data into the model and found that this can only partially constrain the parameters of the model and does not constrain the vertical structure of the chlorophyll. In their second paper ${ }^{(96)}$ they used a simpler fourcompartment ecosystem model (nitrate, phytoplankton, zooplankton, detritus) coupled to the same mixed layer model as in their first paper. ${ }^{(95)}$ They found that surface chlorophyll assimilation is not sufficient to reproduce the seasonal cycle of surface chlorophyll, temperature, and nitrate in a robust manner. By additionally assimilating surface nitrate and temperature the model is 
improved. Comparison between the two models suggests that choice of model structure can affect the results obtained. Although satellite ocean color data have not been used in these studies, they are important as they show that satellite-derived surface chlorophyll values on their own may not provide sufficient information to constrain models through data assimilation. Despite this, it is undoubtedly the case that as new ocean color data become available from the next generation of sensors, they will be used in assimilation studies (along with other data) to improve the biophysical modeling of the oceans.

\subsection{Dimethyl Sulfide, Climate, and Gaia}

It is known that various species of phytoplankton produce dimethyl sulfoniopropionate (DMSP), a precursor of DMS. ${ }^{(1,97)}$ Some time ago Charlson et al. ${ }^{(98)}$ proposed a link between the DMS originating in the ocean due to phytoplankton and the formation of cloud condensation nuclei $(\mathrm{CCN})$ in the atmosphere. The DMS is oxidized in the atmosphere to form sulfate particles which act as $\mathrm{CCN}$. Changing the $\mathrm{CCN}$ concentration affects the formation of clouds, which in turn influences cloud albedo and hence the climate. Changes in the climate in turn affect the phytoplankton in the ocean, thus providing a feedback mechanism. Under the Gaia hypothesis of the Earth as a self-regulating system, ${ }^{(97,99)}$ the increased albedo of the earth would reduce the temperature and light beneath the clouds, and so reduce photosynthesis and the growth of DMS-producing phytoplankton. Less DMS would in turn mean fewer $\mathrm{CCN}$, fewer clouds, and an increase in light allowing more phytoplankton to grow. These feedbacks would allow the climate system to remain in balance.

In order to understand this process better, attempts have been made to estimate the flux of DMS from the ocean to the atmosphere. One of these has made use of CZCS ocean color data. ${ }^{(100)}$ Using an empirical relationship between the CZCS chlorophyll data and DMS, together with a gas transfer coefficient estimated using climatological winds (see section 4.2.1), Thompson et al. ${ }^{(100)}$ are able to estimate the flux of DMS from atmosphere to ocean. They note that the complexity of the phytoplankton production of DMS means that a valid relationship between the two will only exist in certain regions and at certain seasons. This is due to the fact that the production of the DMS precursor DMSP is highly species-specific. ${ }^{(1)}$ There are also considerable (factor 2) uncertainties associated with the DMS gas transfer coefficient. ${ }^{(101)}$ Nevertheless Thompson et al. ${ }^{(100)}$ were able to obtain estimates that are consistent, for a specific region and season, with in situ measurements and an estimate based on photochemical model and atmospheric measurements. They note that future ocean color sensors with increased spectral resolution may enable a more robust determination of the relationship between phytoplankton and DMS to be established, by providing quantitative information on species abundance or on the productivity of those phytoplankton groups that are strong producers of DMS. It should be noted that anthropogenic emissions of sulfur far exceed those from phytoplankton. Therefore, their impact on the climate system, particularly in the industrialized northern hemisphere, is greater. ${ }^{(1,5)}$

\subsection{Commercial Application - Fisheries}

Although the primary focus of this article has been on the use of remotely sensed ocean color data for research into biological oceanography, it is worthwhile mentioning briefly that the data have also been successfully used for commercial purposes. The importance of commercial applications of the data is evidenced by the fact that SeaWiFS was launched and is operated by a commercial company OSC. The primary commercial application of ocean color data is in fisheries. ${ }^{(102)}$ It has been used, often in conjunction with SST data, to guide fishermen and fishing vessels to areas where fish might be found. This use is based on the food chain principle that an abundance of phytoplankton leads to an abundance of zooplankton that feed on them. This in turn leads to an abundance of fish that eat the zooplankton. Thus the presence of high levels of phytoplankton, as measured by changes in ocean color, is taken to indicate the potential presence of fish. More sophisticated approaches that take into account the preferences of certain fish species for particular temperature conditions (hence the use of SST in conjunction with ocean color), can be used to determine where to fish. ${ }^{(103)}$ Even in a situation where fish catches are limited by legislation (as is the cases for European Community countries), the time and fuel saved in searching for fish may improve the profitability of fishing, a tangible benefit to the fisherman or fishing fleet operator. SeaWiFS data are being used to provide such services for fishermen, as CZCS data were in the past.

\subsection{Possible Future Applications}

In this final section a number of possible future applications of ocean color measurements from space will be briefly discussed. These are not exhaustive, but are given here to show the potential for the use of ocean color data. Despite the many existing applications that have been discussed above, which were based primarily on the use of CZCS data, the data from the new improved ocean color sensors (OCTS, SeaWiFS, MODIS, MERIS) will doubtless lead to the development of many new applications. 


\subsubsection{Discrimination of Different Phytoplankton Species}

As discussed in section 4.1.3 it has already proved possible to gain information from ocean color measurements on one particular species of phytoplankton, namely coccolithophores. One paper ${ }^{(104)}$ has shown that it may be possible to detect blooms of the cyanobacterium Trichodesmium (a species of phytoplankton), using CZCS data. With the increased spectral discrimination and more bands that will be available from future sensors (MODIS, MERIS) it may be possible to discriminate between different species on the basis of their photosynthetic pigments. Different combinations and amounts of pigments in different species will produce varying responses in the light spectrum, as measured by the color sensors. The standard algorithms being proposed for MODIS include one for the detection of coccolithophores. ${ }^{(9)}$ No doubt other algorithms will be developed as the data become available, as was the case for CZCS.

\subsubsection{Measurement of Other Biochemical Constituents}

In the earlier discussion of applications (sections 4.1, 4.2, and 4.5) it was shown that even the rather limited CZCS data were able to provide some information on a variety of biochemical constituents apart from chlorophyll-a. The new generation of sensors should allow further studies of DMS, carbonyl sulfide, $p \mathrm{CO}_{2}$, and other chemical constituents related to the phytoplankton. MODIS algorithms have been developed to retrieve information on the algal pigment phycoerythrin. ${ }^{(9)}$ In addition, MODIS and MERIS are capable of measuring the phytoplankton fluorescence peak at around $685 \mathrm{~nm}$ (see Tables 6 and 8 , and Esaias et al. $\left.{ }^{(9)}\right)$. Of the light energy absorbed by phytoplankton chlorophyll, a small amount $\mathrm{O}(1 \%)$ is re-emitted as fluorescence. ${ }^{(11)}$ This provides an alternative means of measuring chlorophyll-a, as demonstrated by Neville and Gower ${ }^{(105)}$ using airborne measurements. Again as data become available, more new algorithms will be developed.

\subsubsection{Use of Data with Models and in situ Measurements}

One area that has been hampered by the lack of ocean color data is that of the use of data with models and in situ measurements. This is a developing area of study, both in terms of the use of data for model validation, and for the improvement of models by data assimilation (see section 4.4). Computer power has increased in such a way that high-resolution coupled biophysical models of entire ocean basins are now possible. Ocean color data can contribute to the validation of such models, ${ }^{(57)}$ to the study of specific processes, ${ }^{(66,106)}$ and to the improvement of the models through data assimilation. ${ }^{(94)}$ Interestingly all these examples are of the North Atlantic Ocean, one of the most studied ocean basins. The improved quality of the data from the new generation of sensors will add impetus to such studies. However, there will be a continuing need to make in situ observations to complement those from ocean color sensors, in order to understand and model other components of the ecosystem and their changes with depth.

\subsubsection{Monitoring of Harmful Algal Blooms}

The environmental and economic impact of harmful algal blooms (HABs) have increased as human activities influence the coastal ecosystem. Various types of phytoplankton produce toxins that can poison fish, thus affecting fisheries and commercial fish farming, or through shellfish that can enter the food chain and cause the poisoning of human beings (for a recent review see Richardson ${ }^{(107)}$ ). The early detection of such blooms could help in preventing or alleviating some of the consequences that follow. In some literature HABs are referred to as "red tides" indicating that the presence of these harmful phytoplankton changes the water color to red or brown. The resulting color change can in principle be detected using ocean color measurements, though it may not be possible to distinguish changes in color due to harmful and nonharmful phytoplankton. ${ }^{(108)}$ The new generation of ocean color sensors provides the opportunity to detect HABs from space and to monitor their development and impact.

\subsection{Afterword}

The preceding review of the use of remotely sensed ocean color data to study biological oceanography makes no claims to be comprehensive or exhaustive (at least a book would be required to do the job properly). Instead the aim has been to give an overview of what has been achieved using the somewhat limited CZCS data set that has been available. The potential of data that are becoming, or will become, available from the new generation of satellite ocean color sensors (OCTS, SeaWiFS, MODIS, MERIS) has also been indicated. The availability of these data mean that an exciting period in the development of satellite-based biological oceanography is just beginning.

\section{ACKNOWLEDGMENTS}

I am grateful to Paolo Cipollini for helpful comments on the first draft of this article.

\section{ABBREVIATIONS AND ACRONYMS}

\section{ADEOS Advanced Earth Observation} Satellite 


$\begin{array}{ll}\text { AOP } & \text { Apparent Optical Properties } \\ \text { AVHRR } & \begin{array}{l}\text { Advanced Very High Resolution } \\ \text { Radiometer }\end{array} \\ \text { CCN } & \text { Cloud Condensation Nuclei } \\ \text { CZCS } & \text { Coastal Zone Color Scanner } \\ \text { DLR } & \text { German Space Agency } \\ \text { DMS } & \text { Dimethyl Sulfide } \\ \text { DMSP } & \text { Dimethyl Sulfoniopropionate } \\ \text { EOS } & \text { Earth Observing System } \\ \text { ESA } & \text { European Space Agency } \\ \text { GAC } & \text { Global Area Coverage } \\ \text { HAB } & \text { Harmful Algal Bloom } \\ \text { HNLC } & \text { High Nitrate (or Nutrient) Low } \\ \text { IFOV } & \text { Chlorophyll } \\ \text { IOP } & \text { Instantaneous Field of View } \\ \text { IR } & \text { Inherent Optical Properties } \\ \text { LAC } & \text { Infrared } \\ \text { MERIS } & \text { Local Area Coverage } \\ \text { MODIS } & \text { Medium Resolution Imaging Spectrometer } \\ \text { Moderate Resolution Imaging } \\ \text { MOS } & \text { Spectroradiometer } \\ \text { NASA } & \text { Modular Optoelectronic Scanner } \\ \text { National Aeronautical and Space } \\ \text { NASDA } & \text { Administration } \\ \text { National Space Development Agency } \\ \text { of Japan } \\ \text { NE } 4 \text { Noise Equivalent Temperature Difference } \\ \text { OCTS } & \text { Ocean Color Imager } \\ \text { OSC } & \text { Ocean Color and Temperature Sensor } \\ \text { PAR } & \text { Photosynthetically Active (or Available) } \\ \text { SeaWiFS } & \text { Radiation } \\ \text { Sea-viewing Wide Field-of-view Sensor } & \text { Signal-to-noise Ratio } \\ \text { Sea Surface Temperature } \\ & \end{array}$

\section{RELATED ARTICLES}

\section{Biomolecules Analysis (Volume 1)}

Fluorescence-based Biosensors • High-performance Liquid Chromatography of Biological Macromolecules

Environment: Trace Gas Monitoring (Volume 3)

Airborne Instrumentation for Aerosol Measurements

Field-portable Instrumentation (Volume 4)

Chemical-sensing Networks: Satellite-based

\section{Remote Sensing (Volume 10)}

Remote Sensing: Introduction • Global Land Databases for Environmental Analyses - Hyperspectral Remote Sensing: Data Collection and Exploitation • Polar Environments Assessment by Remote Sensing • Processing and Classification of Satellite Images • Satellite and Sensor Systems for Environmental Monitoring

Electronic Absorption and Luminescence (Volume 12) Fluorescence Imaging Microscopy • Fluorescence Lifetime Measurements, Applications of

\section{REFERENCES}

1. K. Denman, E. Hofmann, H. Marchant, 'Marine Biotic Responses to Environmental Change and Feedbacks to Climate', in Climate Change 1995: the Science of Climate Change, eds. J.T. Houghton, L.G. Meira Fihlo, B.A. Callander, N. Harris, A. Kattenberg, K. Maskell, Cambridge University Press, Cambridge, 483-516, 1996.

2. I.S. Robinson, Satellite Oceanography: An Introduction for Oceanographers and Remote-sensing Scientists, Ellis Horwood, Chichester, 1985.

3. R.H. Stewart, Methods of Satellite Oceanography, University of California Press, Berkeley, 1985.

4. C.S. Nilsson, P.C. Tildesley, 'Imaging of Oceanic Features by ERS 1 Synthetic Aperture Radar', J.Geophys. Res., 100, 953-967 (1995).

5. K.H. Mann, J.R.N. Lazier, Dynamics of Marine Ecosystems: Biological-Physical Interactions in the Oceans, 2nd edition, Blackwell Science, Oxford, 1996.

6. G. Feldman, N. Kuring, C. Ng, W. Esaias, C. McClain, J. Elrod, N. Maynard, D. Endres, R. Evans, J. Brown, S. Walsh, M. Carle, G. Podesta, 'Ocean Color: Availability of the Global Data Set', Eos, Trans. Am. Geophys, Union, 70, 634-635, 640-641 (1989).

7. G.L. Clarke, G.C. Ewing, C.J. Lorenzen, 'Spectra of Backscattered Light from the Sea Obtained from Aircraft as a Measurement of Chlorophyll Concentration', Science, 167, 1119-1121 (1970).

8. R.H. Evans, H.R. Gordon, 'Coastal Zone Color Scanner, "System Calibration": A Retrospective Examination', J. Geophys. Res., 99, $7293-7307$ (1994).

9. W.E. Esaias et al., 'An Overview of MODIS Capabilities for Ocean Science Observations', IEEE Trans. Geosci. Remote Sensing, 36, 1250-1265 (1998).

10. M.A. Rast (ed.), MERIS: The Medium Resolution Imaging Spectrometer, ESA, Noordwijk, 1996.

11. J.T.O. Kirk, Light and Photosynthesis in Aquatic Ecosystems, 2nd edition, Cambridge University Press, Cambridge, 1996.

12. P.G. Falkowski, J.A. Raven, Aquatic Photosynthesis, Blackwell Science, Abingdon, 1997.

13. C.M. Lalli, T.R. Parsons, Biological Oceanography: An Introduction, 2nd edition, Butterworth-Heinemann, Oxford, 1997.

14. C.D. Mobley, Light and Water: Radiative Transfer in Natural Waters, Academic Press, San Diego, 1994. 
15. H.R. Gordon, R.W. Austin, D.K. Clark, W.A. Hovis, C.S. Yentsch, 'Ocean Color Measurements', Adv. Geophys., 27, 297-333 (1985).

16. H.R. Gordon, 'Atmospheric Correction of Ocean Color Imagery in the Earth Observing System Era', J.Geophys. Res., 102, 17081-17106 (1997).

17. A. Longhurst, Ecological Geography of the Sea, Academic Press, San Diego, 1998.

18. O.B. Brown, R.H. Evans, J.W. Brown, H.R. Gordon, R.C. Smith, K.S. Baker, 'Phytoplankton Blooming off the US East Coast: A Satellite Description', Science, 229, 163-167 (1985).

19. A. Morel, L. Prieur, 'Analysis of Variations in Ocean Color’, Limnol. Oceanogr., 22, 709-722 (1977).

20. H.R. Gordon, O.B. Brown, R.H. Evans, J.W. Brown, R.C. Smith, K.S. Baker, D.K. Clark, 'A Semi-analytical Radiance Model of Ocean Color', J. Geophys. Res., 93, 10909-10924 (1988).

21. V. Barale, P.M. Schlittenhardt (eds.), Ocean Color: Theory and Applications in a Decade of CZCS Experience, Kluwer Academic, Dordrecht, 1993.

22. H.R. Gordon, M. Wang, 'Retrieval of Water-leaving Radiances and Aerosol Optical Thickness over the Oceans with SeaWiFS: A Preliminary Algorithm', Appl. Optics., 33, 443-452 (1994).

23. P.M. Holligan, T. Aarup, S.B. Groom, 'The North Sea: Satellite Color Atlas', Cont. Shelf Res., 9, 667-765 (1989).

24. J. Aiken, G.F. Moore, P.M. Holligan, 'Remote Sensing of Oceanic Biology in Relation to Global Climate Change', J. Phycol., 28, 579-590 (1992).

25. S.B. Hooker, C.R. McClain, A. Holmes, 'Ocean Color Imaging: CZCS to SeaWiFS', Mar. Tech. Soc. J., 27, 3-15 (1993).

26. S. Saitoh, 'OCTS on ADEOS', in Oceanographic Applications of Remote Sensing, eds. K. Ikeda, F. Dobson, CRC Press, Boca Raton, FL, 473-480, 1995.

27. S.B. Hooker, W.E. Esaias, 'An Overview of the SeaWiFS Project', Eos, Trans. Am. Geophys. Union, 74, 241, 245-246 (1993).

28. W.L. Barnes, T.S. Pagano, V.V. Salomonson, 'Prelaunch Characteristics of the Moderate Resolution Imaging Spectroradiometer (MODIS) on EOS-AM1', IEEE Trans. Geosci. Remote Sensing, 36, 1088-1100 (1998).

29. C.R. McClain, G. Feldman, W. Esaias, 'Oceanic Biological Productivity', in Atlas of Satellite Observations Related to Global Change, eds. R.J. Gurney, J.L. Foster, C.L. Parkinson, Cambridge University Press, Cambridge, 251-263, 1993.

30. C.W. Sullivan, K.R. Arrigo, C.R. McClain, J.C. Cosimo, J. Firestone, 'Distributions of Phytoplankton Blooms in the Southern Ocean', Science, 262, 1832-1837 (1993).

31. D.K. Clark, H.R. Gordon, K.J. Voss, Y. Ge, W. Broenkow, C. Trees, 'Validation of Atmospheric Correction over the Oceans', J. Geophys. Res., 102, 17209-17217 (1997).
32. C.R. McClain, W.E. Esaias, W. Barnes, B. Guenther, D. Endres, S.B. Hooker, G. Mitchell, R. Barnes, Calibration and Validation Plan for SeaWiFS, NASA Technical Memorandum 104566 Vol. 3, NASA Goddard Space Flight Center, Maryland, 1992.

33. D. McGillicuddy, A.R. Robinson, D.A. Siegel, H.W Jannasch， R. Johnson, T.D. Dickey, J. McNeil, A.F. Michaels, A.H. Knap, 'Influence of Mesoscale Eddies on New Production in the Sargasso Sea', Nature, 394, 263-266 (1998).

34. M.R. Abbott, D.B. Chelton, 'Advances in Passive Remote Sensing of the Ocean', Rev. Geophys., Suppl., $571-589$ (1991).

35. J.A. Yoder, C.R. McClain, G.C. Feldman, W.E. Esaias, 'Annual Cycles of Phytoplankton Chlorophyll Concentrations in the Global Ocean: A Satellite View', Global Biogeochem. Cyc., 7, 181-193 (1993).

36. K. Banse, D.C. English, 'Seasonality of Coastal Zone Color Scanner Phytoplankton Pigment in the Offshore Oceans', J. Geophys. Res., 99, 7323-7345 (1994).

37. C.T. Tynan, 'Ecological Importance of the Southern Boundary of the Antarctic Circumpolar Current', Nature, 392, 708-710 (1998).

38. C.B. Field, M.J. Behrenfeld, J.T. Randerson, P. Falkowski, 'Primary Production of the Biosphere: Integrating Terrestrial and Oceanic Components', Science, 281, 237-240 (1998).

39. A. Longhurst, S. Sathyendranath, T. Platt, C. Caverhill, 'An Estimate of Global Primary Production in the Ocean from Satellite Radiometer Data', J. Plankton Res., 17, 1245-1271 (1995).

40. D. Pauly, V. Christensen, 'Primary Production Required to Sustain Global Fisheries', Nature, 374, 255-257 (1995).

41. T. Platt, S. Sathyendranath, 'Oceanic Primary Production: Estimation by Remote Sensing at Local and Regional Scales', Science, 241, 1613-1620 (1988).

42. J.K. Bishop, W.B. Rossow, 'Spatial and Temporal Variability of Surface Solar Irradiance', J. Geophys. Res., 96, 16839-16858 (1991).

43. M.J. Berhenfeld, P.G. Falkowski, 'A Consumer's Guide to Phytoplankton Primary Productivity Models', Limnol. Oceanogr., 42, 1479-1491 (1997).

44. P.G. Falkowski, R.T. Barber, V. Smetacek, 'Biogeochemical Controls and Feedbacks on Ocean Primary Production', Science, 281, 200-206 (1998).

45. S. Sathyendranath, T. Platt, E.P.W. Horne, W.G. Harrison, O. Ulloa, R. Outerbridge, N. Hoepffner, 'Estimation of New Production in the Ocean by Compound Remote Sensing', Nature, 353, 129-133 (1991).

46. M.D. Keller, W.K. Bellows, R.R.L. Guillard, Dimethyl Sulfide Production in Marine Phytoplankton: Review, American Chemical Society Symposium Series, 167-182, Vol. 393, 1989.

47. C.W. Brown, J.A. Yoder, 'Coccolithophorid Blooms in the Global Ocean', J. Geophys. Res., 99, 7467-7482 (1994). 
48. P.M. Holligan, et al., 'A Biogeochemical Study of the Coccolithophore Emiliania huxleyi in the North Atlantic', Global Biogeochem. Cyc., 7, 879-900 (1993).

49. W.H. Schlesinger, Biogeochemistry: An Analysis of Global Change, 2nd edition, Academic Press, San Diego, 1997.

50. U. Siegenthaler, J.L. Sarmiento, 'Atmospheric Carbon Dioxide and the Ocean', Nature, 365, 119-125 (1993).

51. A.J. Watson, C. Robinson, J.E. Robinson, P.J. le B. Williams, M.J.R. Fasham, 'Spatial Variability in the Sink for Atmospheric Carbon Dioxide in the North Atlantic', Nature, 350, 50-53 (1991).

52. D. Antoine, A. Morel, 'Modelling the Seasonal Course of the Upper Ocean $p \mathrm{CO}_{2}$ (II). Validation of the Model and Sensitivity Studies', Tellus, 47B, 122-144 (1995).

53. D. Antoine, A. Morel, 'Modelling the Seasonal Course of the Upper Ocean $p \mathrm{CO}_{2}(\mathrm{I})$. Development of A Onedimensional Model', Tellus, 47B, 103-121 (1995).

54. D.J. Erickson, B.E. Eaton, 'Global Biogeochemical Cycling Estimates with CZCS Satellite Data and General Circulation Models', Geophys. Res. Lett., 20, 683-686 (1993).

55. P.S. Liss, L. Merlivat, 'Air-sea Gas Exchange Rates: Introduction and Synthesis', in The Role of Air-Sea Gas Exchange in Geochemical Cycling, ed. P. Baut-Menard, D. Reidel, Norwood, 113-128, 1986.

56. J. Etcheto, J. Boutin, L. Merlivat, 'Seasonal Variations of the $\mathrm{CO}_{2}$ Exchange Coefficient over the Global Ocean Using Satellite Wind Speed Measurements', Tellus, 43B, 247-255 (1991).

57. J.L. Sarmiento, R.D. Slater, M.J.R. Fasham, H.W. Ducklow, J.R. Toggweiler, G.T. Evans, 'A Seasonal Threedimensional Ecosystem Model of Nitrogen Cycling in the North Atlantic Euphotic Zone', Global Biogeochem. Cyc., 7, 417-450 (1993).

58. L.R. Haury, J.A. McGowan, P.H. Wiebe, 'Patterns and Processes in the Timescale of Plankton', in Spatial Patterns in Plankton Communities, ed. J. Steele, Plenum Press, New York, 277-327 1978.

59. J.D. Woods, 'Scale Upwelling and Primary Production', in Towards a Theory on Biophysical Interactions in the World Ocean, ed. B.J. Rothschild, Kluwer Academic, Dordrecht, 7-83, 1988.

60. V.H. Strass, 'Chlorophyll Patchiness Caused by Mesoscale Upwelling at Fronts', Deep-Sea Res., 36, 75-96 (1992).

61. C.S. Davis, G.R. Flierl, P.H. Wiebe, P.J.S. Franks, 'Micropatchiness, Turbulence and Recruitment in Plankton', J. Mar Res., 49, 109-151 (1991).

62. K.L. Denman, A.E. Gargett, 'Biological-Physical Interactions in the Upper Ocean: The Role of Vertical and Small Scale Transport Processes', Annu. Rev. Fluid Mech., 27, 225-255 (1995).

63. H.U. Sverdrup, 'On Conditions for the Vernal Blooming of Phytoplankton', J. Cons. Per. Int. Exp. Mer., 18, 287-295 (1953)
64. S.G.H. Philander, El Nino, La Nina, and the Southern Oscillation, Academic Press, San Diego, 1990.

65. D. Halpern, G. Feldman, 'Annual and Interannual Variations of Phytoplankton Pigment Concentration and Upwelling Along the Pacific Equator', J. Geophys. Res., 99, 7347-7354 (1994).

66. A. Oschlies, V. Garcon, 'Eddy-induced Enhancement of Primary Production in a Model of the North Atlantic Ocean', Nature, 394, 266-269 (1998).

67. G. Garcia-Moliner, J.A. Yoder, 'Variability in Pigment Concentration in Warm-core Rings as Determined by Coastal Zone Color Scanner Satellite Imagery from the Mid-Atlantic Bight', J. Geophys. Res., 99, 14277-14290 (1994).

68. D.B. Olson, 'Rings in the Ocean', Ann. Rev. Earth Planet. Sci., 19, 283-311 (1991).

69. S.J. Weeks, F.A. Shillington, 'Interannual Scales of Variation of Pigment Concentrations from Coastal Zone Color Scanner Data in the Benguela Upwelling System and the Subtropical Convergence Zone South of Africa', J. Geophys. Res., 99, 7385-7399 (1994).

70. K.L. Denman, M.R. Abbott, 'Time Scales of Pattern Evolution from Cross-spectrum Analysis of Advanced Very High Resolution Radiometer and Coastal Zone Color Scanner Imagery', J. Geophys. Res., 99, 7433-7442 (1994).

71. F.M. Sousa, A. Bricaud, 'Satellite-derived Phytoplankton Pigment Structures in the Portuguese Upwelling Area', J. Geophys. Res., 97, 11343-11356 (1992).

72. M.R. Abbott, P.M. Zion, 'Satellite Observations of Phytoplankton Variability during an Upwelling Event', Cont. Shelf Res., 6, 661-680 (1985).

73. R.E. Thompson, J.F.R. Gower, 'A Wind-induced Mesoscale Eddy over the Vancouver Island Continental Slope', J. Geophys. Res., 90, 8981-8993 (1985).

74. C.A.E. Garcia, I.S. Robinson, 'Sea Surface Velocities in Shallow Seas Extracted from Sequential CZCS Satellite Data', J. Geophys. Res., 94, 12681-12691 (1989).

75. M.R. Lewis, J.J. Cullen, T. Platt, 'Phytoplankton and Thermal Structure in the Upper Ocean: Consequences of Nonuniformity in the Chlorophyll Profile', J. Geophys. Res., 88, 2565-2570 (1983).

76. J.T.O. Kirk, 'Solar Heating of Water Bodies as Influenced by their Inherent Optical Properties', J. Geophys. Res., 93, 10897-10908 (1988).

77. M.R. Lewis, M.E. Carr, G.C. Feldman, W. Esaias, C. McClain, 'Influence of Penetrating Solar Radiation on the Heat Budget of the Equatorial Pacific', Nature, 347, 543-545 (1990).

78. M.J.R. Fasham, 'Modelling the Marine Biota', in The Global Carbon Cycle, ed. M. Heimann, Springer-Verlag, New York, 457-504, 1993.

79. M.R. Abbott, 'Report of the US JGOFS Workshop on Modeling and Data Assimilation', US JGOFS Planning Report 14, 1992. 
80. J.L. Sarmiento, R.A. Armstrong, 'US JGOFS Synthesis and Modeling Project Implementation Plan', US JGOFS Report, 1997.

81. E. Hofmann, T. Osborne, T. Powell, J. Price, B. Rothschild, J. Roughgarden, 'Theory and Modeling in GLOBEC: A First Step', US GLOBEC Report, 1991.

82. A.E. Gill, Atmosphere-Ocean Dynamics, Academic Press, San Diego, 1982.

83. G.T. Evans, J.S. Parslow, 'A Model of Annual Plankton Cycles', Biol. Oceanogr., 3, 327-347 (1985).

84. M.J.R. Fasham, H.W. Ducklow, S.M. McKelvie, 'A Nitrogen Based Model of Plankton Dynamics in the Oceanic Mixed Layer', J. Mar. Res., 48, 591-639 (1990).

85. W.C. Thacker, R.B. Long, 'Fitting Dynamics to Data', J. Geophys. Res., 93, 1227-1240 (1988).

86. M. Ghil, P. Malanotte-Rizzoli, 'Data Assimilation in Meteorology and Oceanography', Adv. Geophys., 33, 141-266 (1991).

87. P. Malanotte-Rizzoli (ed.), Modern Approaches to Data Assimilation in Ocean Modeling, Elsevier, New York, 1996.

88. A.F. Michaels, A.H. Knap, R.L. Dow, K. Gundersen, R.J. Johnson, J. Sorensen, A. Close, 'Seasonal Patterns of Ocean Biogeochemistry at the US JGOFS Bermuda Atlantic Time-series Study Site', Deep-sea Res. I, 41, 1013-1038 (1994).

89. H.W. Ducklow, R.P. Harris, 'Introduction To the JGOFS North Atlantic Bloom Experiment', Deep-sea Res., 40, 1-8 (1993).

90. J. Ishizaka, 'Coupling of CZCS Data to a Physical-Biological Model of the Southeastern US Continental Shelf Ecosystem, 3. Nutrient and Phytoplankton Fluxes and CZCS Data Assimilation', J. Geophys. Res., 95, 20201-20212 (1990).

91. J. Ishizaka, 'Coupling of CZCS Data to a PhysicalBiological Model of the Southeastern US Continental Shelf Ecosystem, 2. An Eulerian Model', J. Geophys. Res., 95, 20183-20199 (1990).

92. J. Ishizaka, 'Coupling of CZCS Data to a Physical-Biological Model of the Southeastern US Continental Shelf Ecosystem, 1. CZCS Data Description and Lagrangian Particle Tracer Experiments', J. Geophys. Res., 95, 20176-20181 (1990).

93. J. Ishizaka, 'Data Assimilation for Biogeochemical Models', in Towards a Model of Ocean Biogeochemical Processes, eds. G.T. Evans, M.J.R. Fasham, SpringerVerlag, New York, 295-316, 1993.

94. R.A. Armstrong, J.L. Sarmiento, R.D. Slater, 'Monitoring Ocean Productivity by Assimilating Satellite Chlorophyll into Ecosystem Models', in Ecological Time Series, eds. T.M. Powell, J.H. Steele, Chapman and Hall, New York, 379-390, 1995.
95. P. Prunet, J.-F. Minster, D. Ruiz-Pino, I. Dadou, 'Assimilation of Surface Data in a One dimensional Physical-Biogeochemical Model of the Surface Ocean 1. Method and Preliminary Results', Global Biogeochem. Cyc., 10, 111-138 (1996).

96. P. Prunet, J.-F. Minster, V. Echevin, I. Dadou, 'Assimilation of Surface Data in a One dimensional Physical-Biogeochemical Model of the Surface Ocean 2. Adjusting a Simple Trophic Model to Chlorophyll, Temperature, Nitrate, and $p \mathrm{CO}_{2}$ Data', Global Biogeochem. Cyc., 10, 139-158 (1996).

97. T.M. Lenton, 'Gaia and Natural Selection', Nature, 394, 439-447 (1998).

98. R.J. Charlson, J.E. Lovelock, M.O. Andreae, S.G. Warren, 'Oceanic Phytoplankton, Atmospheric Sulfur, Cloud Albedo and Climate', Nature, 326, 655-661 (1987).

99. J. Lovelock, Gaia: A New Look at Life on Earth, Oxford University Press, Oxford, 1995.

100. A.M. Thompson, W.E. Esaias, R.L. Iverson, 'Two Approaches to Determining the Sea-to-air Flux of Dimethyl sulfide: Satellite Ocean Color and a Photochemical Model with Atmospheric Measurements', J. Geophys. Res., 95, 20551-20558 (1990).

101. M.O. Andreae, P.J. Crutzen, 'Atmospheric Aerosols: Biogeochemical Sources and Role in Atmospheric Chemistry', Science, 276, 1052-1058 (1997).

102. P.C. Fielder, G.B. Smith, R.M. Laurs, 'Fisheries Applications of Satellite Data in the Eastern North Pacific', Mar Fish. Rev., 46, 1-13 (1984).

103. R.M. Laurs, P.C. Fielder, D.R. Montgomery, 'Albacore Tuna Catch Distributions Relative to Environmental Features Observed from Satellites', Deep-sea Res., 31, 1085-1099 (1984).

104. A. Subramaniam, E.J. Carpenter, 'An Empirically Derived Protocol for the Detection of Blooms of the Marine Cyanobacterium Trichodesmium using CZCS Imagery', Int. J. Remote Sensing, 15, 1559-1569 (1994).

105. R.A. Neville, J.F.R. Gower, 'Passive Remote Sensing of Phytoplankton via Chlorophyll $\alpha$-Fluorescence', $J$. Geophys. Res., 82, 3487-3493 (1977).

106. R.G. Williams, M.J. Follows, 'The Ekman Transfer of Nutrients and Maintenance of New Production over the North Atlantic', Deep-sea Res. I, 45, 461-489 (1998).

107. K. Richardson, 'Harmful or Exceptional Phytoplankton Blooms in the Marine Ecosystem', Adv. Mar. Biol., 31, 302-385 (1997).

108. J.J. Cullen, A.M. Ciotti, R.F. Davis, M.R. Lewis 'Optical Detection and Assessment of Algal Blooms', Limnol. Oceanogr., 42, 1223-1239 (1997). 